\title{
DIAGNÓSTICO DO SISTEMA DE GESTÃO DOS PARQUES NATURAIS MUNICIPAIS DO NORTE DO RIO GRANDE DO SUL
}

\author{
DIAGNOSIS OF THE NATURAL CITY PARKS MANAGEMENT SYSTEM \\ IN THE NORTH REGION OF RIO GRANDE DO SUL
}

\author{
Carmem Fátima Casanova* \\ Adalberto Pandolfo** \\ Natalia Hauenstein Eckert*** \\ Ritielli Berticelli**** \\ Naira Barbacovi***** \\ Marcele Salles Martins $* * * * * *$ \\ Aline Pimentel Gomes*******
}

\section{RESUMO}

A grande maioria dos parques brasileiros continua irregular, mesmo depois de anos da criação da primeira Unidade de Conservação. As novas regras e leis vigentes ainda não garantem as melhores formas de gestão dessas áreas, que atualmente se apresentam ineficientes na administração e repassadas à população com qualidade ínfima de uso. $\bigcirc$ objetivo desta pesquisa se baseou em avaliar o sistema de gestão das Unidades de Conservação do tipo Parques Naturais Municipais no norte do Rio Grande do Sul, visando proporcionar um levantamento do seu atual

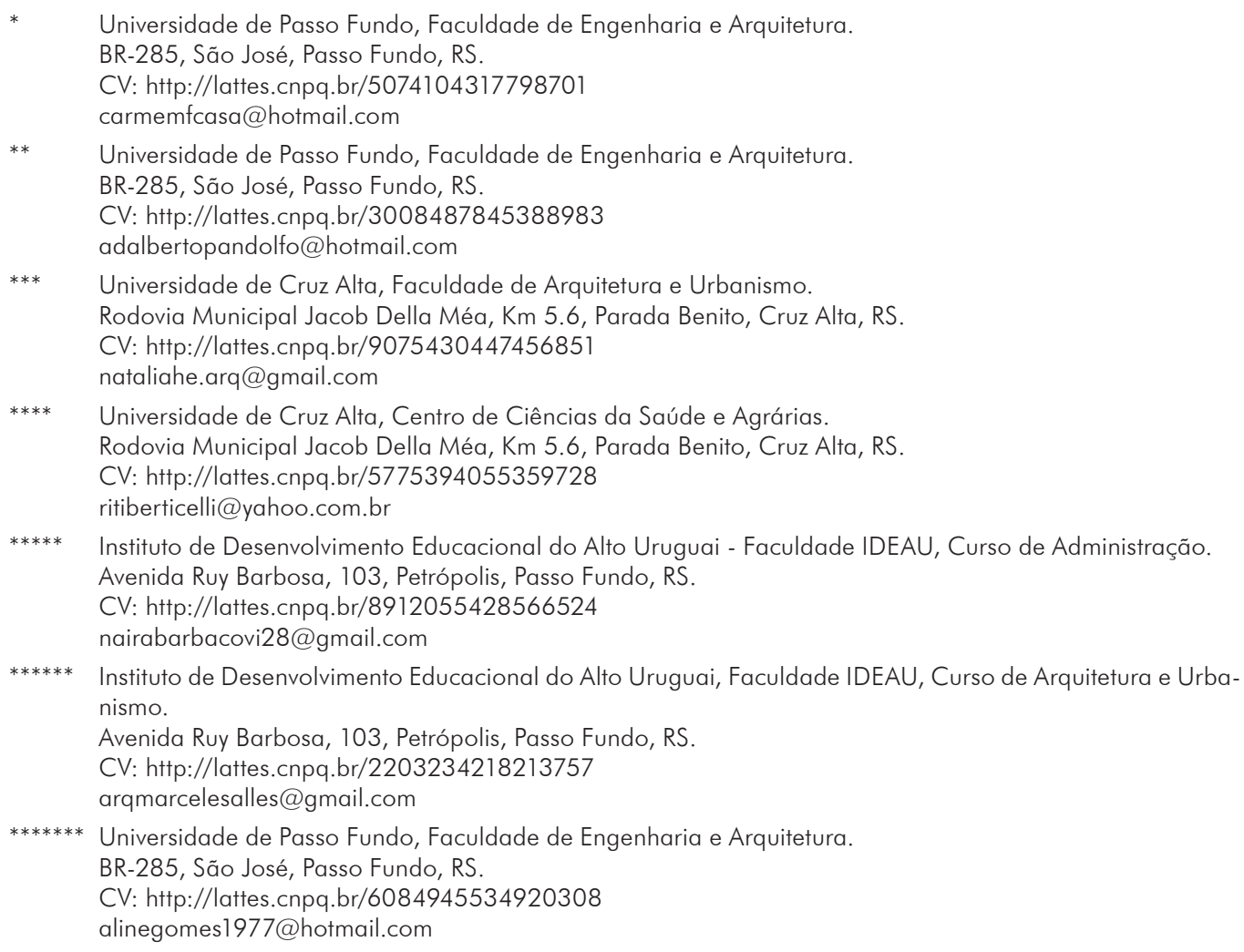


gerenciamento através de um diagnóstico por meio da avaliação de quatro fatores: ambientais, sociais, econômico--financeiros e institucionais. A metodologia de abordagem utilizou questionários aplicados aos gestores e visitas às áreas. Os pontos positivos e negativos em cada um dos parques foram pontuados como forma de compreensão dos problemas, para que ações futuras possam ocorrer de forma eficiente na preservação das áreas protegidas do norte do estado do Rio Grande do Sul.

Palavras-chave: Preservação. Gestão. Unidades de Conservação. Parques.

\section{ABSTRACT}

The situation of the majority of national parks in the country remains irregular, even years after the establishment of the first Conservation Unit. New regulations and current laws still do not guarantee the best management system of these areas, which are inadequately offered to public use. The objective of this research is to evaluate the management system of Conservation Units of the category "Natural City Parks" in the north region of Rio Grande do Sul. Four factors were analyzed during the survey and diagnosis of the current management of these parks: environmental, social, economic/financial and institutional. By means of questionnaires given to managers and visits to the areas, some positive and negative aspects in each of the parks were analyzed as ways of understanding the existing problems, so that future action can be efficiently taken in order to preserve the protected areas in the north region of Rio Grande do Sul State. Keywords: Preservation. Management. Conservation unit. Parks.

\section{INTRODUÇÃO}

De acordo com Galvão et al. (2006), o termo gestão ambiental é bastante abrangente, frequentemente usado para designar ações ambientais em determinados espaços geográficos, como: gestão ambiental de bacias hidrográficas, gestão ambiental de parques e reservas florestais, gestão de áreas de proteção ambiental, gestão ambiental de reservas de biosfera e outras modalidades de gestão que incluam aspectos ambientais. Segundo o autor, a gestão ambiental pode ser vista como um conjunto de políticas, programas, práticas administrativas e operacionais que levam em conta a saúde e a segurança das pessoas, visando à proteção do meio ambiente através da eliminação ou minimização de impactos e danos ambientais. Para tanto, quando se busca uma gestão ambiental eficiente, faz-se necessário analisar todas as fases do projeto: planejamento, implantação, operação, avaliação, ampliação, realocação ou desativação de empreendimentos ou atividades, incluindo todas as fases do ciclo de vida de um produto. A figura 1 apresenta o ciclo de gestão adaptativa de acordo com as fases em que retroalimentam os ciclos naturais, objetivando preservar os ecossistemas, incentivar a pesquisa científica, os estudos e o monitoramento ambiental, promovendo a educação ambiental, a visitação pública e o turismo ecológico, assegurando o uso sustentável de recursos naturais (RAMOS et al., 2012).

O manejo e a gestão adequados de uma Unidade de Conservação (UC) devem estar embasados não só no conhecimento dos elementos que conformam o espaço em questão, mas também na interpretação da interação desses elementos. É essencial conhecer os ecossistemas, os processos naturais e as interferências antrópicas positivas ou negativas que os influenciam ou os definem - considerando os usos que o homem faz do território, analisando aspectos passados e impactos atuais ou futuros, de forma a elaborar meios para conciliar o uso dos espaços com os objetivos de criação da UC (ICMBio, 2013). 


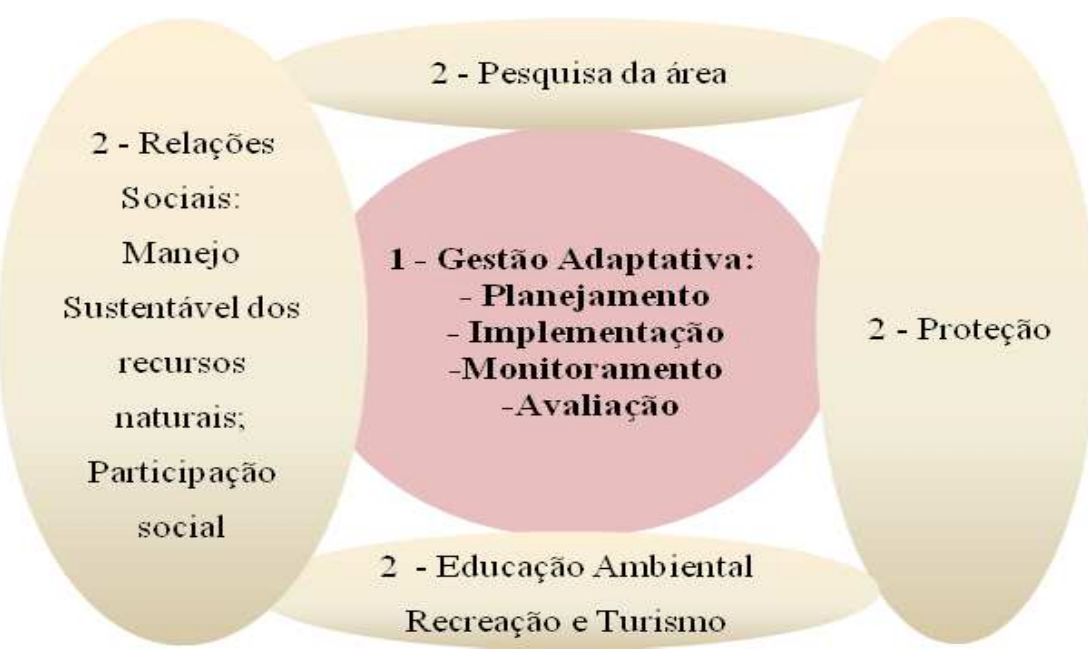

Figura 1 Modelo conceitual de gestão de Unidades de Conservação. Fonte: Adaptado de Ramos et al., 2012, por Casanova et al., 2014.

A criação de Áreas Protegidas (APs) tem sido a principal estratégia global para a conservação da biodiversidade e dos modos de vida tradicionais no mundo (LEVERINGTON et. al., 2010; CHAPE et. al., 2005; MEDEIROS, IRVING, GARAY, 2004; RODRIGUES et. al., 2004). O Instituto Chico Mendes de Conservação da Biodiversidade (ICMBio), criado em 2007, relatou os primeiros critérios e regras na criação e gestão das UCs. No entanto demonstra através de relatórios, que cada vez mais em função da conscientização da conservação tem-se criado novas unidades. Entretanto, não existem informações e conhecimentos suficientes para um gerenciamento adequado. Além disso, a simples delimitação territorial e legal de regimes especiais de uso é insuficiente para a conservação da biodiversidade, se não houver a gestão adequada desses espaços (CALANDINO, 2016). Por essa razão, analisando-se sob uma perspectiva histórica, foram criados diferentes modelos de gestão, que potencializaram evidentes descontinuidades nas etapas gerenciais das unidades durante a alternância dos períodos de gestão pública e diluíram os esforços na busca dos objetivos precípuos dessas áreas (SANTOS et al., 2012).

Oliveira (2012) descreve que, no âmbito da gestão das áreas protegidas, a efetividade de gestão seria condição de eficiência e gestão em decorrência de um impacto positivo no estado de conservação da biodiversidade e/ou nas comunidades diretamente envolvidas na utilização sustentável dos recursos naturais. A avaliação da efetividade de gestão mede como as UCs protegem os valores que almejam proteger e quão eficientemente estão sendo alcançadas suas metas e objetivos (HOCKINGS et al., 2006). Para assegurar que os esforços para conservação da biodiversidade e uso sustentável dos recursos naturais, aliados à geração de bens e melhoria da qualidade de vida, sejam efetivos na implementação das UCs, torna-se necessária a construção de instrumentos de monitoramento do manejo dessas áreas, de forma a subsidiar a tomada de decisões (RAMOS et al., 2013). 
Carmem Fátima Casanova, Adalberto Pandolfo, Natalia Hauenstein Eckert, Ritielli Berticelli, Naira Barbacovi, Marcele Salles Martins, Aline Pimentel Gomes

Este estudo tem como objetivo analisar como se dá a gestão de cinco parques municipais e como os mesmos consideram os aspectos ambientais, sociais, econômico-financeiros e institucionais em seus planos de gestão. Conforme o Sistema Nacional de Unidades de Conservação (SNUC), o Plano de Manejo é um documento técnico mediante o qual estarão os fundamentos de gestão e os objetivos gerais de uma UC. $O$ documento estabelece o zoneamento e as normas que devem presidir o uso da área e o manejo dos recursos naturais, inclusive a implantação das estruturas físicas necessárias à gestão da UC (BRASIL, 2000).

\section{METODOLOGIA}

O diagnóstico da gestão dos parques foi realizado em quatro etapas. Na avaliação de cada etapa foram apresentadas as características ambientais, sociais, econômico-financeiras e institucionais, com seus indicadores e práticas. Para a pesquisa selecionaram-se cinco Parques Naturais Municipais (PNMs): 1. PNM de Sertão (Sertão); 2. PNM Longines Malinowski (Erechim); 3. PNM da Sagrisa (Pontão); 4. PNM do Apertado (Severiano de Almeida); 5. PNM do rio Uruguai Teixeira Soares (Marcelino Ramos).

\section{ETAPA 1: IDENTIFICAÇÃO E AVALIAÇÃO DO ÂMBITO AMBIENTAL ATRAVÉS DE INDICADORES NOS PARQUES}

No âmbito ambiental são avaliados os aspectos relacionados com a categoria de manejo, biodiversidade e diversidade cultural relevantes da região, presentes na área, e as condições da UC em relação à viabilidade ecológica (RAMOS et al., 2013). Ervin (2003), Hockings, (2003) e Parrish, Braun, Unnasch (2003) descrevem que as avaliações das UCs no grupo da integridade ecológica considera aspectos como: integridade, viabilidade das espécies, processos ecológicos, ameaças e pressões às quais a UC está submetida.

Nesta etapa realizou-se o diagnóstico e foram avaliados aspectos relacionados com a categoria de manejo, a biodiversidade e a diversidade culturais. Considerou-se quais aspectos eram mais relevantes para a região e a existência destes na área e nas condições da UCs em relação à viabilidade ecológica. Para tanto elaborou-se um conjunto de questões que nortearam os indicadores, categoria de manejo e se a área possuía condições de viabilidade ecológica (quadro 1). 
Quadro 1 Âmbito ambiental, aspectos e indicadores

\begin{tabular}{|c|c|c|}
\hline \multicolumn{3}{|c|}{ I - ÂMBITO AMBIENTAL } \\
\hline Indicador 1 & Indicador 2 & Indicador 3 \\
\hline Categoria de manejo & & $\begin{array}{c}\text { A área possui } \\
\text { condições de } \\
\text { viabilidade ecológica }\end{array}$ \\
\hline $\begin{array}{l}\text { Prática } 1 \text { - serão avaliados os } \\
\text { objetivos de conservação e a } \\
\text { categoria de manejo e seus } \\
\text { usos. }\end{array}$ & $\begin{array}{l}\text { Prática } 3 \text { - será avaliado se a área } \\
\text { conserva amostras representativas } \\
\text { de ecossistemas. }\end{array}$ & $\begin{array}{l}\text { Prática } 6 \text { - será avaliado } \\
\text { se a área possui } \\
\text { conectividade entre outras } \\
\text { UCs e ou APPs. }\end{array}$ \\
\hline \multirow[t]{2}{*}{$\begin{array}{l}\text { Prática } 2 \text { - serão avaliados os } \\
\text { usos que se desevolvem na UC e } \\
\text { se estes são compatíveis com a } \\
\text { categoria de uso. }\end{array}$} & $\begin{array}{l}\text { Prática } 4 \text { - será avaliado se a } \\
\text { área conserva atrativos naturais } \\
\text { relevantes. }\end{array}$ & \multirow{2}{*}{$\begin{array}{l}\text { Prática } 7 \text { - será avaliado } \\
\text { se o zoneamento da UC } \\
\text { favorece a viabilidade } \\
\text { ecológica. }\end{array}$} \\
\hline & $\begin{array}{l}\text { Prática } 5 \text { - será avaliado se a área } \\
\text { contribui para a conservação da } \\
\text { diversidade biológica. }\end{array}$ & \\
\hline
\end{tabular}

Fonte: Adaptado de Ramos et al., (2012), por Casanova et al., 2014.

\section{ETAPA 2: IDENTIFICAÇÃO E AVALIAÇÃO NO ÂMBITO SOCIAL ATRAVÉS DE INDICADORES NOS PARQUES}

Nesta etapa fez-se a avaliação quanto ao âmbito social dos parques, através de questionário avaliativo. A aplicação das questões foi direcionada aos gestores responsáveis por cada um dos parques. Foram avaliados aspectos relacionados aos programas educativos ofertados nos parques, os recursos disponíveis, o tipo de sustentabilidade para a manutenção da UC e o modo de convivência da população com a área. $\bigcirc$ quadro 2 apresenta os indicadores sociais e as práticas selecionadas para esta etapa.

Quadro 2 Âmbito social, indicadores e práticas

\section{ASPECTO SOCIAL}

Indicador 4 - Estratégias e aplicações de integração da comunidade do entorno e população em geral.

Prática 8 - será avaliado se o parque possui Conselho Gestor e se este facilita o manejo adequado da área.

Prática 9 - serão avaliadas quais são as estratégias de integração entre a população e o parque.

Prática 10 - será avaliado se a população do entorno é envolvida com a implementação de estratégias para melhoria contínua.

Prática 11 - será avaliado se o parque e a população interagem na gestão.

Prática 12 - será avaliado se a comunidade se manifesta favorável ao manejo do parque.

Fonte: Adaptado de Ramos et al., (2012), por Casanova et al., 2014. 
Carmem Fátima Casanova, Adalberto Pandolfo, Natalia Hauenstein Eckert, Ritielli Berticelli, Naira Barbacovi, Marcele Salles Martins, Aline Pimentel Gomes

\section{ETAPA 3: IDENTIFICAÇÃO E AVALIAÇÃO NO ÂMBITO ECONÔMICO-FINANCEIRO ATRAVÉS DOS INDICADORES NOS PARQUES}

A etapa 3 consistiu na identificação dos aspectos econômico-financeiros dos parques. $\bigcirc$ quadro 3 apresenta os indicadores selecionados para essa etapa, com base nos estudos realizados por Ramos et al., (2012).

Quadro 3 Âmbitos econômico-financeiros indicadores e práticas

\section{ÂMBITO ECONÔMICO-FINANCEIRO}

\begin{tabular}{|c|c|}
\hline $\begin{array}{l}\text { Indicador } 5 \text { - O Parque influi positivamente } \\
\text { no desenvolvimento econômico da cidade }\end{array}$ & $\begin{array}{l}\text { Indicador } 6 \text { - O parque conta com recursos financeiros } \\
\text { necessários à gestão adequada }\end{array}$ \\
\hline $\begin{array}{l}\text { Prática } 13 \text { - será avaliado se a população em geral } \\
\text { recebe benefícios diretos em razão da existência } \\
\text { do parque. }\end{array}$ & $\begin{array}{l}\text { Prática17 - será avaliado se o parque possui gastos e se conhe- } \\
\text { cem os custos reais do manejo da área. }\end{array}$ \\
\hline $\begin{array}{l}\text { Indicador } 5 \text { - O Parque influi positivamente } \\
\text { no desenvolvimento econômico da cidade }\end{array}$ & $\begin{array}{c}\text { Indicador } 6 \text { - O parque conta com recursos financeiros } \\
\text { necessários à gestão adequada }\end{array}$ \\
\hline $\begin{array}{l}\text { Prática } 14 \text { - será avaliado se a população do } \\
\text { entorno recebe benefícios diretos em razão da } \\
\text { existência do parque. }\end{array}$ & $\begin{array}{l}\text { Prática } 18 \text { - será avaliado se possui receitas, despesas, e } \\
\text { quais são. }\end{array}$ \\
\hline $\begin{array}{l}\text { Prática } 15 \text { - será avaliado se a infraestrutura ou } \\
\text { serviços de interesse da comunidade local são } \\
\text { desenvolvidos em razão do parque. }\end{array}$ & $\begin{array}{l}\text { Prática } 19 \text { - será avaliado se o parque conta com fontes } \\
\text { diversas de valores recebidos e quais são. }\end{array}$ \\
\hline \multirow{10}{*}{$\begin{array}{l}\text { Prática } 16 \text { - será avaliado se existem projetos } \\
\text { de desenvolvimento comunitário promovidos } \\
\text { pela administração do parque. }\end{array}$} & $\begin{array}{l}\text { Prática } 20 \text { - será avaliado se as receitas cobrem os custos } \\
\text { de manutenção do parque. }\end{array}$ \\
\hline & $\begin{array}{l}\text { Prática } 21 \text { - será avaliado se o parque possui fontes } \\
\text { de financiamento e se são adequadas e diversas para a } \\
\text { manutenção da UC em longo prazo. }\end{array}$ \\
\hline & $\begin{array}{l}\text { Prática } 22 \text { - será avaliado se existem e quais são as } \\
\text { estratégias para obter recursos financeiros. }\end{array}$ \\
\hline & $\begin{array}{l}\text { Prática } 23 \text { - será avaliado se existem e quais são as vendas } \\
\text { de bens e serviços aos usuários do parque. }\end{array}$ \\
\hline & $\begin{array}{l}\text { Prática } 24 \text { - será avaliado se existe venda de serviços } \\
\text { ambientais e de ecoturismo e quais são. }\end{array}$ \\
\hline & $\begin{array}{l}\text { Prática } 25 \text { - será avaliado se existe gestão adequada e } \\
\text { quais os mecanismos utilizados. }\end{array}$ \\
\hline & $\begin{array}{l}\text { Prática } 26 \text { - será avaliado se ocorre manejo financeiro } \\
\text { institucional e como é realizado. }\end{array}$ \\
\hline & $\begin{array}{l}\text { Prática } 27 \text { - será avaliado se ocorre transferência de } \\
\text { recursos financeiros ajustados ao que é solicitado e como é } \\
\text { realizado. }\end{array}$ \\
\hline & $\begin{array}{l}\text { Prática } 28 \text { - será avaliado se existem recursos gerados e se } \\
\text { estes são aplicados na melhoria da gestão do parque. }\end{array}$ \\
\hline & $\begin{array}{l}\text { Prática } 29 \text { - será avaliado se o parque possui mecanismos } \\
\text { de controle financeiro e como são realizados. }\end{array}$ \\
\hline
\end{tabular}

Fonte: Adaptado de Ramos et al., (2012), por Casanova et al., 2014. 


\section{ETAPA 4: IDENTIFICAÇÃO E AVALIAÇÃO NO ÂMBITO INSTITUCIONAL ATRAVÉS DE INDICADORES NOS PARQUES}

Nesta etapa foram avaliados os indicadores quanto ao âmbito institucional, considerando aspectos relacionados ao planejamento, à legislação e infraestrutura, aos equipamentos, recursos humanos e outros que influenciam na gestão. $\bigcirc$ quadro 4 apresenta a relação de indicadores e práticas baseados no estudo de Ramos et al. (2012).

Quadro 4 Âmbito institucional, aspectos e indicadores

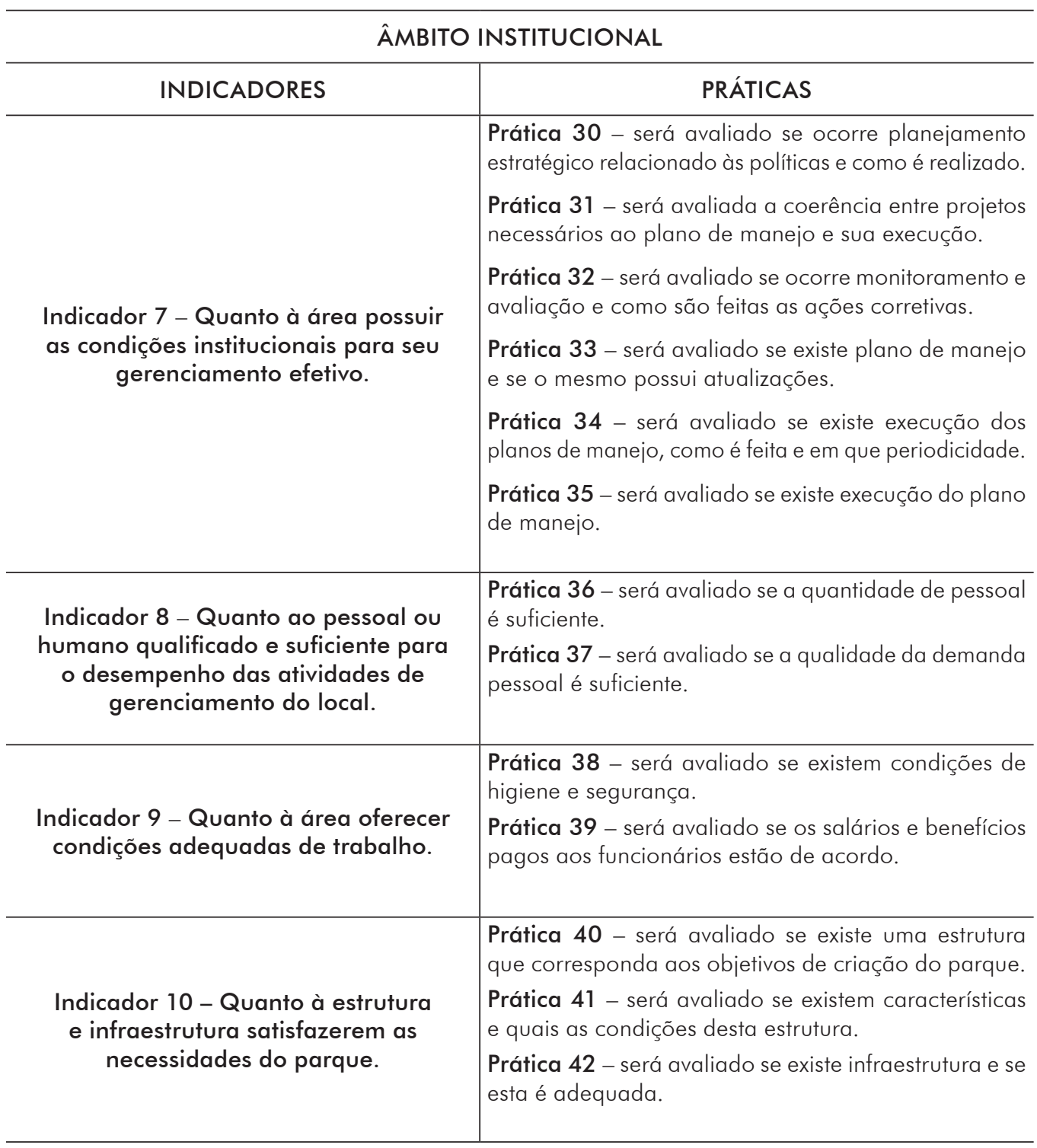




\begin{tabular}{|c|c|}
\hline \multirow{7}{*}{$\begin{array}{c}\text { Indicador } 11 \text { - Quanto à legislação, } \\
\text { normas, técnicas e disposições } \\
\text { administrativas. }\end{array}$} & $\begin{array}{l}\text { Prática } 43 \text { - será avaliado se há uma administração } \\
\text { e se possui apoio para a gestão do parque. }\end{array}$ \\
\hline & $\begin{array}{l}\text { Prática } 44 \text { - será avaliado se existem equipamentos e } \\
\text { ferramentas para o trabalho e se estes são suficientes. }\end{array}$ \\
\hline & $\begin{array}{l}\text { Prática } 45 \text { - será avaliado se possui status legal de } \\
\text { criação da área. }\end{array}$ \\
\hline & $\begin{array}{l}\text { Prática } 46 \text { - será avaliado se possui regulamento de } \\
\text { uso dos recursos naturais. }\end{array}$ \\
\hline & $\begin{array}{l}\text { Prática } 47 \text { - será avaliado se o regulamento também } \\
\text { prevê uma gestão financeira. }\end{array}$ \\
\hline & $\begin{array}{l}\text { Prática } 48 \text { - será avaliado se existe regulamento } \\
\text { administrativo. }\end{array}$ \\
\hline & $\begin{array}{l}\text { Prática } 49 \text { - será avaliado se existem leis relacionadas } \\
\text { ao planejamento, manejo e gestão do parque. }\end{array}$ \\
\hline \multirow{2}{*}{$\begin{array}{l}\text { Indicador } 12 \text { - Quanto aos mecanismos } \\
\text { de solução, conflitos relacionados } \\
\text { ao domínio, posse de terras e uso de } \\
\text { recursos naturais serem efetivos. }\end{array}$} & $\begin{array}{l}\text { Prática } 50 \text { - será avaliado se são usadas estratégias para } \\
\text { a resolução de conflitos relacionados com o domínio } \\
\text { legal das terras. }\end{array}$ \\
\hline & $\begin{array}{l}\text { Prática } 51 \text { - será avaliado se existem estratégias, e } \\
\text { quais são, para a resolução de conflitos relacionados } \\
\text { com o domínio legal das terras. }\end{array}$ \\
\hline \multirow{3}{*}{$\begin{array}{c}\text { Indicador } 13 \text { - Quanto à área contar } \\
\text { com estrutura organizativa adequada ao } \\
\text { manejo. }\end{array}$} & $\begin{array}{l}\text { Prática } 52 \text { - será avaliado se possui estrutura organi- } \\
\text { zacional. }\end{array}$ \\
\hline & $\begin{array}{l}\text { Prática } 53 \text { - será avaliado se possui sistema funcional } \\
\text { de comunicação interna. }\end{array}$ \\
\hline & $\begin{array}{l}\text { Prática } 54 \text { - será avaliado se possui mecanismos de } \\
\text { registro de ações para a informação da gestão da UC. }\end{array}$ \\
\hline
\end{tabular}

Fonte: Adaptado de Ramos et al. (2013), por Casanova et al., 2014.

\section{RESULTADOS E DISCUSSÕES}

O estudo buscou avaliar como se dá a gestão de cinco PMNs através dos aspectos ambientais, sociais, econômico-financeiros e institucionais - para os quais se criou um conjunto de indicadores, conforme estudo de Ramos et. al. (2012) e de práticas que viessem a responder os indicadores. Para tabulação dos dados atribuiu-se o valor de dez pontos para todas as práticas atendidas e zero para nenhuma prática atendida. A figura 2 apresenta o esquema avaliativo com os indicadores e valores atribuídos de acordo com cada prática.

A avaliação dos indicadores se deu através dos valores atribuídos em cada prática atendida para cada parque, gerando uma tabela de valores atendidos e não atendidos a cada prática questionada pelos gestores dos PNM (quadro 5). A coleta das informações se deu através da aplicação de questionário e visitas in loco. 
Quadro 5 Avaliação no âmbito ambiental

\begin{tabular}{|c|c|c|c|c|c|c|c|c|}
\hline \multicolumn{9}{|c|}{ ÂMBITO AMBIENTAL } \\
\hline Práticas & $\begin{array}{c}\text { PNM } \\
\text { Apertado }\end{array}$ & $\begin{array}{c}\text { Constatação } \\
\text { in loco }\end{array}$ & $\begin{array}{l}\text { PNM } \\
\text { Sertão }\end{array}$ & $\begin{array}{c}\text { Constatação } \\
\text { in loco }\end{array}$ & $\begin{array}{c}\text { PNM } \\
\text { Sagrisa }\end{array}$ & $\begin{array}{l}\text { Constatação } \\
\text { in loco }\end{array}$ & $\begin{array}{l}\text { PNM } \\
\text { LM }\end{array}$ & $\begin{array}{c}\text { Constatação } \\
\text { in loco }\end{array}$ \\
\hline \multicolumn{9}{|c|}{ Indicador 1 - Categoria de manejo } \\
\hline $\begin{array}{l}\text { P1 - Existe } \\
\text { coerência entre } \\
\text { as características } \\
\text { intrínsecas, os } \\
\text { objetivos de } \\
\text { conservação e } \\
\text { a categoria de } \\
\text { manejo? }\end{array}$ & 1,6665 & 1,6665 & 1,6665 & 1,6665 & 1,6665 & 1,6665 & 1,6665 & 1,6665 \\
\hline $\begin{array}{l}\text { P2 - Os usos que } \\
\text { se desevolvem } \\
\text { na UC são } \\
\text { compatíveis com } \\
\text { a categoria de } \\
\text { uso? }\end{array}$ & 1,6665 & 0,00 & 1,6665 & 0,00 & 1,6665 & 0,00 & 1,6665 & 1,6665 \\
\hline SUBTOTAL & 3,333 & 1,6665 & 3,333 & 1,6665 & 3,333 & 1,6665 & 3,333 & 3,333 \\
\hline \multicolumn{9}{|c|}{ Indicador 2 - Área total e de delimitação para a conservação da biodiversidade } \\
\hline $\begin{array}{l}\text { P3 - A área } \\
\text { conserva } \\
\text { amostras } \\
\text { representativas } \\
\text { de ecossistemas } \\
\text { relevantes da } \\
\text { região? }\end{array}$ & 1,111 & 1,111 & 1,111 & 1,111 & 1,111 & 1,111 & 1,111 & 1,111 \\
\hline $\begin{array}{l}\text { P4 - A área } \\
\text { conserva } \\
\text { atrativos naturais } \\
\text { relevantes a } \\
\text { região? }\end{array}$ & 1,111 & 1,111 & 1,111 & 1,111 & 1,111 & 1,111 & 1,111 & 1,111 \\
\hline $\begin{array}{l}\text { P5 - A área } \\
\text { contribui para } \\
\text { a conservação } \\
\text { da diversidade } \\
\text { biológica? }\end{array}$ & 1,111 & 1,111 & 1,111 & 1,111 & 1,111 & 1,111 & 1,111 & 1,111 \\
\hline SUBTOTAL & 3,333 & 3,333 & 3,333 & 3,333 & 3,333 & 3,333 & 3,333 & 3,333 \\
\hline
\end{tabular}

Indicador 3 - Área que constitui as condições necessárias para favorecimento da viabilidade ecológica

\begin{tabular}{|c|c|c|c|c|c|c|c|c|}
\hline $\begin{array}{l}\text { P6 - A área } \\
\text { possui } \\
\text { conectividade } \\
\text { entre UC e } \\
\text { outras áreas } \\
\text { de preservação } \\
\text { ambiental? }\end{array}$ & 0,00 & 0,00 & 0,00 & 0,00 & 1,6665 & 1,6665 & 0,00 & 0,00 \\
\hline $\begin{array}{l}\text { P7 - O } \\
\text { zoneamento } \\
\text { da UC favore } \\
\text { a viabilidade } \\
\text { ecológica? }\end{array}$ & 0,00 & 1,6665 & 1,6665 & 1,6665 & 0,00 & 1,6665 & 1,6665 & 1,6665 \\
\hline SUBTOTAL & 0,00 & 1,6665 & 1,6665 & 1,6665 & 1,6665 & 3,333 & 1,6665 & 1,6665 \\
\hline $\begin{array}{l}\text { Total de } \\
\text { pontuação nos } \\
\text { municípios }\end{array}$ & 6,666 & 6,666 & 8,3325 & 6,666 & 6,1105 & 8,3325 & 8,3325 & 8,3325 \\
\hline
\end{tabular}

Fonte: Autores, 2014. 
Carmem Fátima Casanova, Adalberto Pandolfo, Natalia Hauenstein Eckert, Ritielli Berticelli, Naira Barbacovi, Marcele Salles Martins, Aline Pimentel Gomes

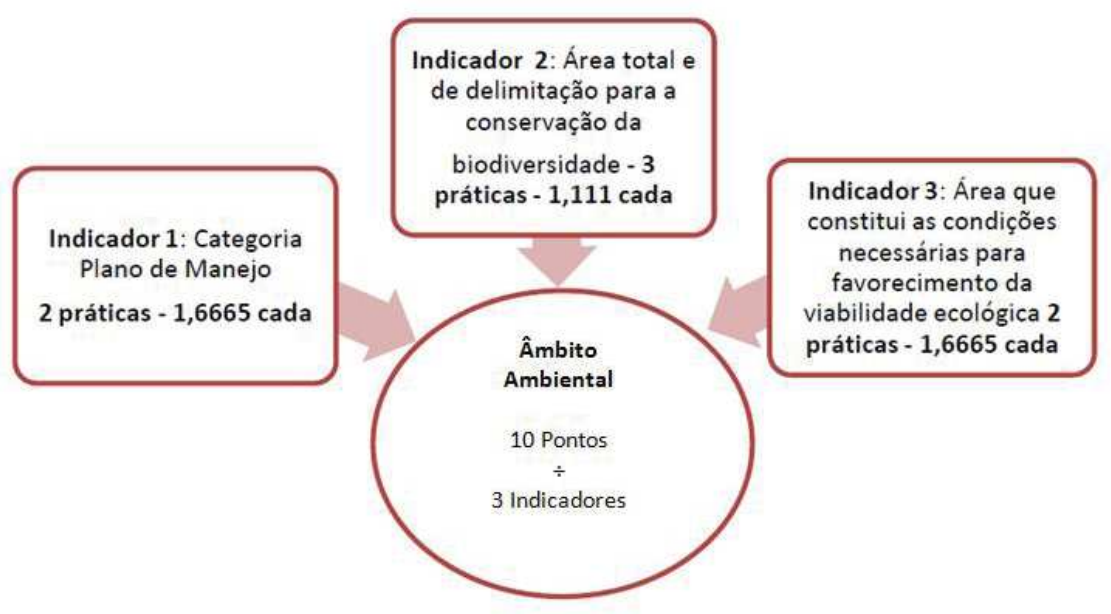

Figura 2 Esquema avaliativo.

Fonte: Autores, 2014.

A figura 3 apresenta a pontuação máxima atendida para cada PNM, de acordo com os indicadores.

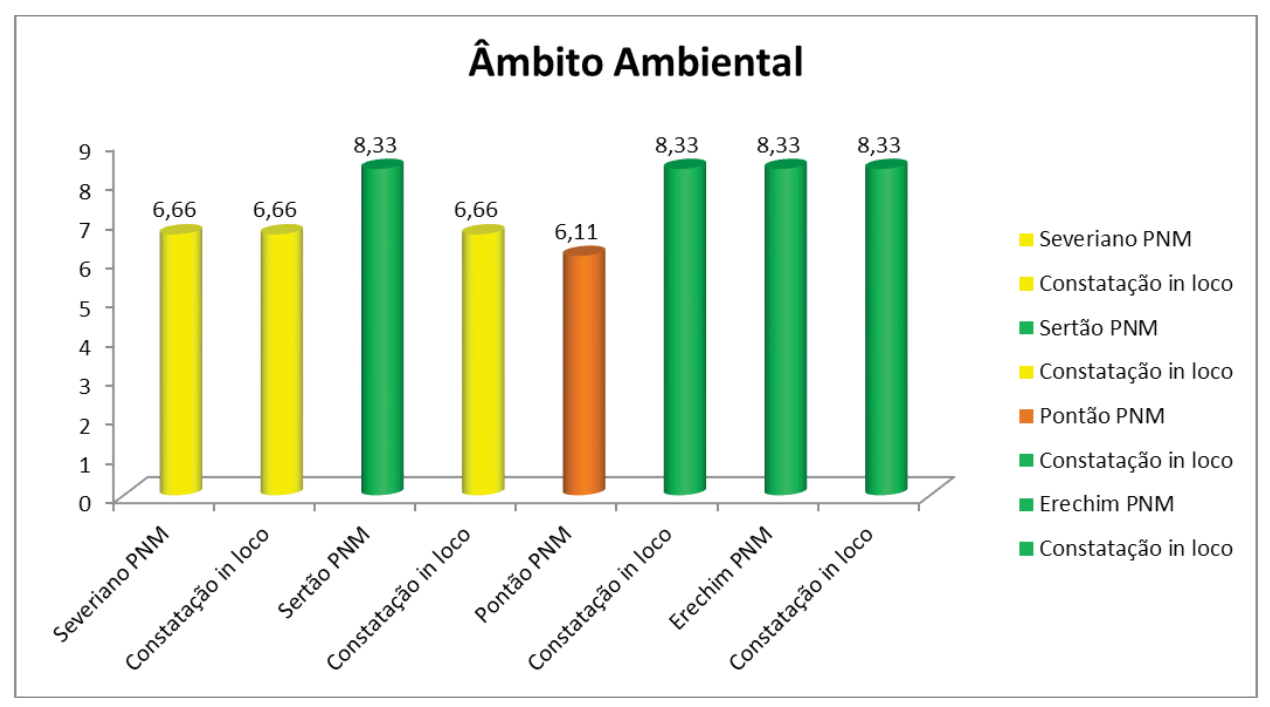

Figura 3 Gráfico demonstrativo da pontuação máxima atendida para cada PNM.

Fonte: Autores, 2014.

De acordo com o quadro 5, observa-se que o Parque Natural Municipal de Sertão (PNMS) e o Parque Natural Municipal Longines Malinowski (PNMLM) atenderam 8,33 pontos do máximo de 10,0 pontos divididos nos indicadores de Categoria de Manejo: área total de delimitação para a conservação da biodiversidade e área que constitui as condições necessárias para o favorecimento da viabilidade ecológica. 
Pode-se perceber o contraponto na comparação da pontuação entre os parques: alguns se aproximaram da pontuação máxima nas categorias dos indicadores 1, 2 e 3. O Parque Natural Municipal da Sagrisa (PNMDS) atingiu 6,11 pontos, e o Parque Natural Municipal do Apertado (PNMA), 6,66 pontos - quantificando o valor mínimo para esses indicadores.

A maior parte da área do Parque Natural do Apertado está localizada em Área de Preservação Permanente (APP), caracterizada como de máxima restrição, constituída legalmente e localizada em APPs, como as encostas íngremes, topos de morro, nascentes, margens de corpos hídricos.

A análise dos indicadores no âmbito ambiental pela visita in loco foi realizada segundo $\mathrm{o}$ atendimento das práticas para cada indicador no âmbito ambiental. A figura 4 retrata as fotos durante a visita ao PNMLM de Erechim.
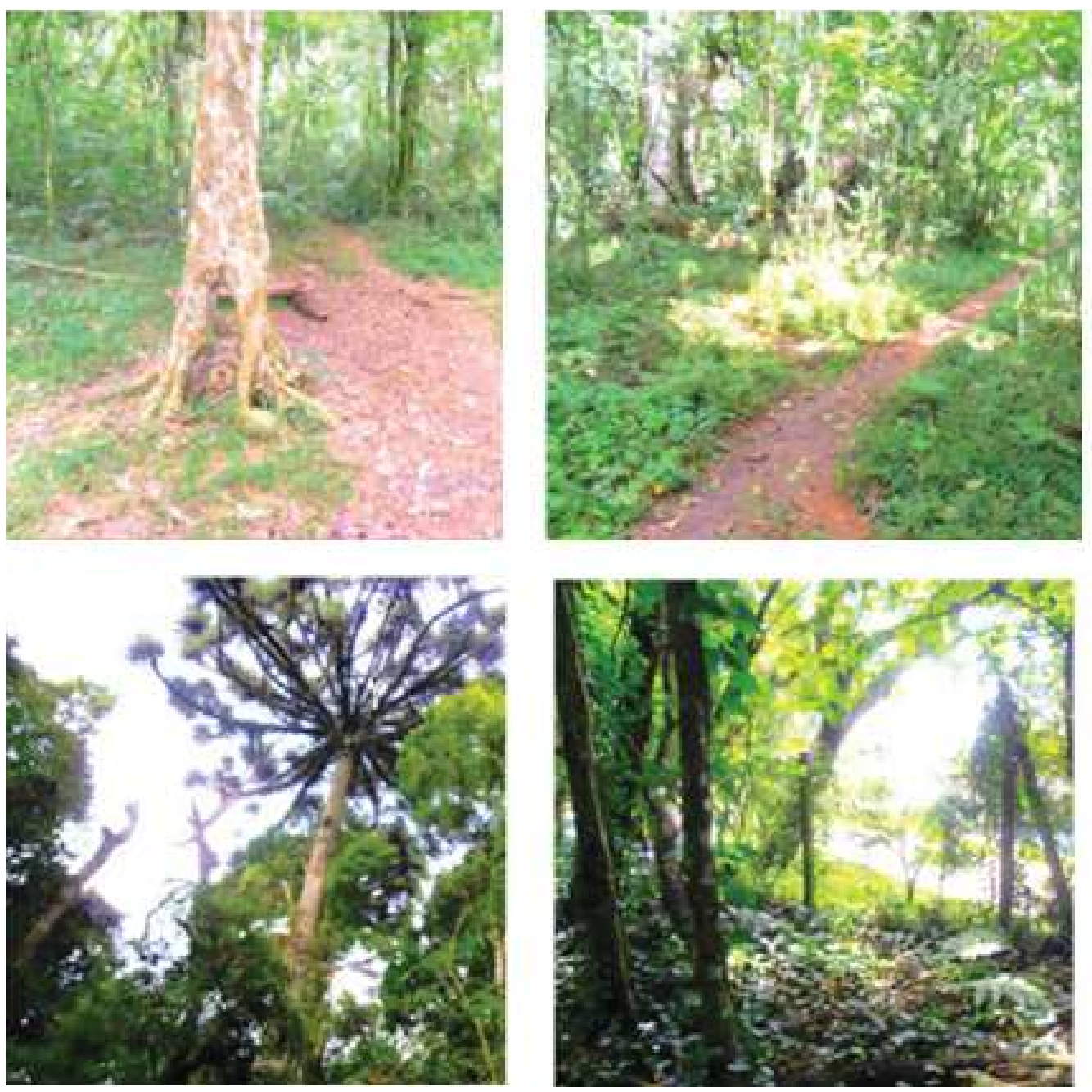

Figura 4 Fotos do PNMLM em práticas atendidas nos indicadores do âmbito ambiental. Fonte: Autores, 2014 
Carmem Fátima Casanova, Adalberto Pandolfo, Natalia Hauenstein Eckert, Ritielli Berticelli, Naira Barbacovi, Marcele Salles Martins, Aline Pimentel Gomes

A análise consistiu em fotografar momentos ou detalhes pertinentes e verificar documentos como o Plano de Manejo dos PNM e restrições para o uso das áreas do entorno. Conforme observa-se na figura 4 , dois parques tiveram pontuação máxima de 8,33 pontos, o PNMDS, de Pontão, e o PNMLM de Erechim. Já o PNMS de Sertão e o PNMA de Severiano atingiram 6,66 pontos.

De acordo com a figura 5, que apresenta o PNMLM, nota-se que estão sendo atendidos os indicadores: categoria de manejo, área de delimitação para a conservação da biodiversidade e área que constitui as condições necessárias para favorecimento da viabilidade ecológica.
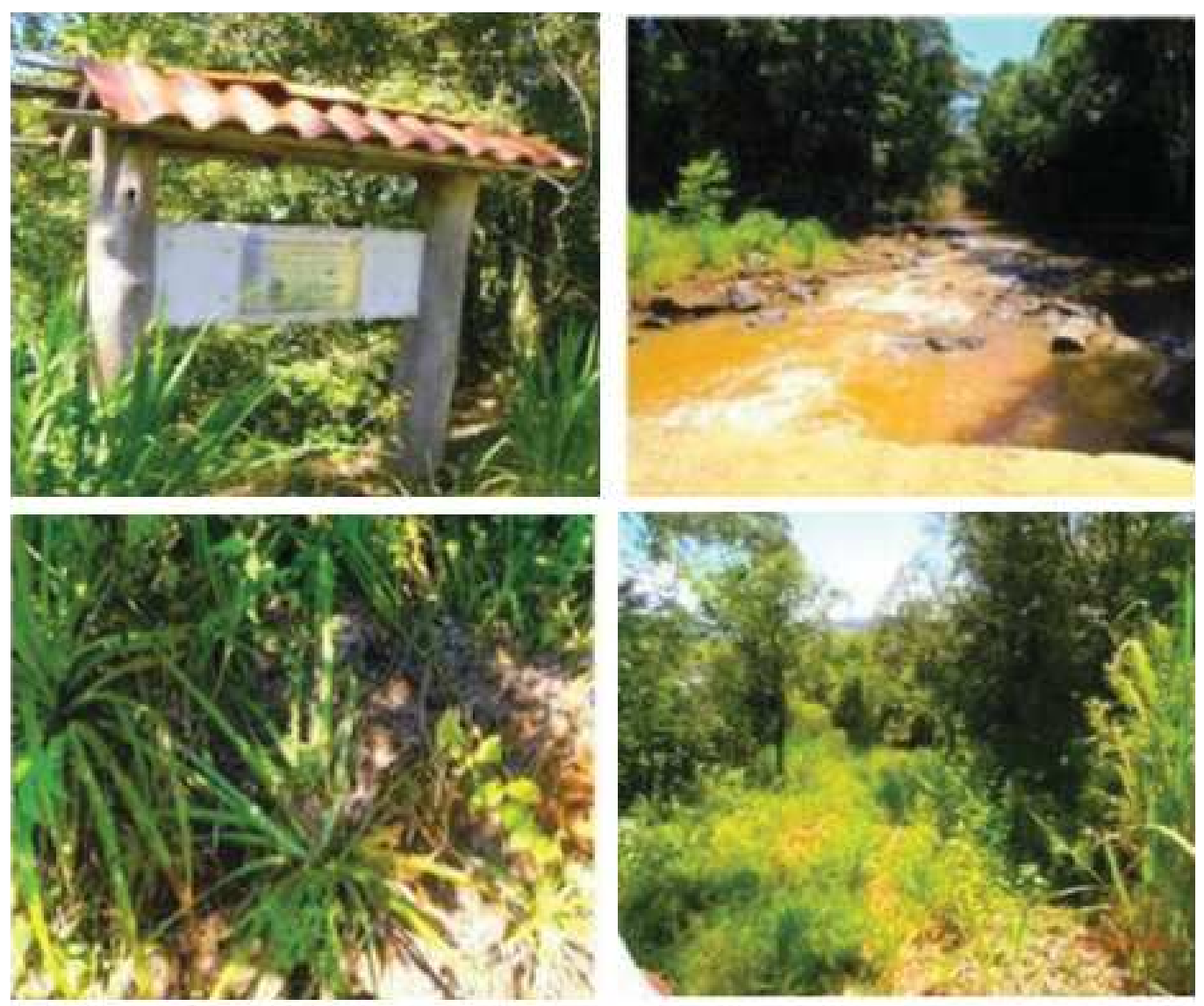

Figura 5 Fotos do PNMA em práticas atendidas dos indicadores do âmbito ambiental.

Fonte: Autores, 2014.

Em entrevista com o gestor responsável pelo PNMA, e através da análise documental, constatou-se que a área possui vários fragmentos de remanescentes de mata atlântica em processo de regeneração em diversos estágios de sucessão ecológica. $\mathrm{Na}$ identificação e avaliação no âmbito social dos indicadores dos parques, avaliou-se a visão dos gestores sobre as práticas atendidas em três indicadores, com sete práticas, 
sendo cada prática uma pergunta do questionário. A figura 6 apresenta o processo explicativo sobre a identificação do âmbito social.

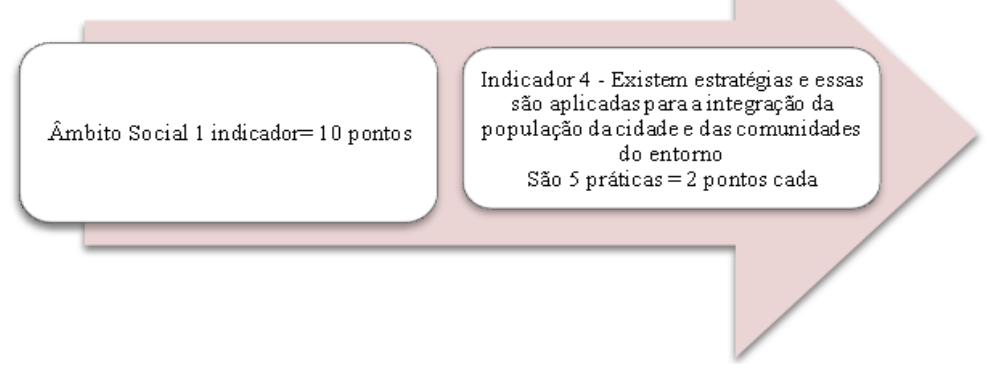

Figura 6 Esquema explicativo.

Fonte: Autores, 2014.

A avaliação dos indicadores partiu dos valores atribuídos em cada prática atendida para cada um deles, gerando uma tabela de valores atendidos e não atendidos (quadro 6).

Quadro 6 Avaliação no âmbito social

\section{ÂMBITO SOCIAL}

Indicador 4 - Existem estratégias e são aplicadas para a integração da população da cidade e das comunidades do entorno

\begin{tabular}{|c|c|c|c|c|c|c|c|c|}
\hline Práticas & $\begin{array}{c}\text { PNAS } \\
\text { Severiano } \\
\end{array}$ & $\begin{array}{c}\text { Constatação } \\
\text { in loco }\end{array}$ & $\begin{array}{c}\text { PNS } \\
\text { Sertão }\end{array}$ & $\begin{array}{c}\text { Constatação } \\
\text { in loco }\end{array}$ & $\begin{array}{l}\text { PNMS } \\
\text { Pontão }\end{array}$ & $\begin{array}{c}\text { Constatação } \\
\text { in loco }\end{array}$ & $\begin{array}{c}\text { PNM } \\
\text { Erechim }\end{array}$ & $\begin{array}{c}\text { Constatação } \\
\text { in loco }\end{array}$ \\
\hline $\begin{array}{l}\text { P8 - O parque } \\
\text { possui Conselho } \\
\text { Gestor e se este } \\
\text { facilita o manejo } \\
\text { adequado da } \\
\text { área? }\end{array}$ & 0,00 & 0,00 & 0,00 & 0,00 & 0,00 & 0,00 & 0,00 & 0,00 \\
\hline $\begin{array}{l}\text { P9 - A UC possui } \\
\text { estratégias de } \\
\text { integração com a } \\
\text { população? }\end{array}$ & 0,00 & 0,00 & 2,00 & 0,00 & 2,00 & 0,00 & 2,00 & 2,00 \\
\hline $\begin{array}{l}\text { P10 - A } \\
\text { população } \\
\text { do entorno é } \\
\text { envolvida com a } \\
\text { implementação } \\
\text { de estratégias } \\
\text { para uma } \\
\text { melhoria } \\
\text { continuada? }\end{array}$ & 2,00 & 0,00 & 0,00 & 0,00 & 0,00 & 0,00 & 2,00 & 2,00 \\
\hline $\begin{array}{l}\text { P11 - A UC e as } \\
\text { comunidades } \\
\text { locais realizam } \\
\text { ações conjuntas? }\end{array}$ & 2,00 & 2,00 & 0,00 & 0,00 & 2,00 & 2,00 & 2,00 & 2,00 \\
\hline
\end{tabular}


Carmem Fátima Casanova, Adalberto Pandolfo, Natalia Hauenstein Eckert, Ritielli Berticelli, Naira Barbacovi, Marcele Salles Martins, Aline Pimentel Gomes

\begin{tabular}{l|c|c|c|c|c|c|c|c}
\hline $\begin{array}{l}\text { P12-A comunidade } \\
\text { manifesta atitudes } \\
\text { favoráveis ao ma- } \\
\text { nejo da UC e seu } \\
\text { entorno? }\end{array}$ & 2,00 & 0,00 & 2,00 & 0,00 & 2,00 & 0,00 & 2,00 & 2,00 \\
\hline $\begin{array}{l}\text { Pontuação total em } \\
\text { cada município: }\end{array}$ & 6,00 & 2,00 & 4,00 & 0,00 & 6,00 & 2,00 & 8,00 & 8,00 \\
\hline
\end{tabular}

Fonte: Autores, 2014.

De acordo com o quadro 6, os resultados apareceram em pontuação máxima de 8 pontos e mínima de 4 . Através da figura 7 é possível verificar os valores máximos e mínimos obtidos.

De acordo com a análise, o PNMLM estava atendendo a 8,00 pontos das práticas perguntadas, ao passo que o PNMA e o PNMDS alcançaram 6,00 pontos. O PNMS alcançou apenas 4,00 pontos para o atendimento das práticas perguntadas sobre o indicador. As questões abordaram a existência de estratégias e se as mesmas eram aplicadas para a integração da população da cidade e das comunidades do entorno.

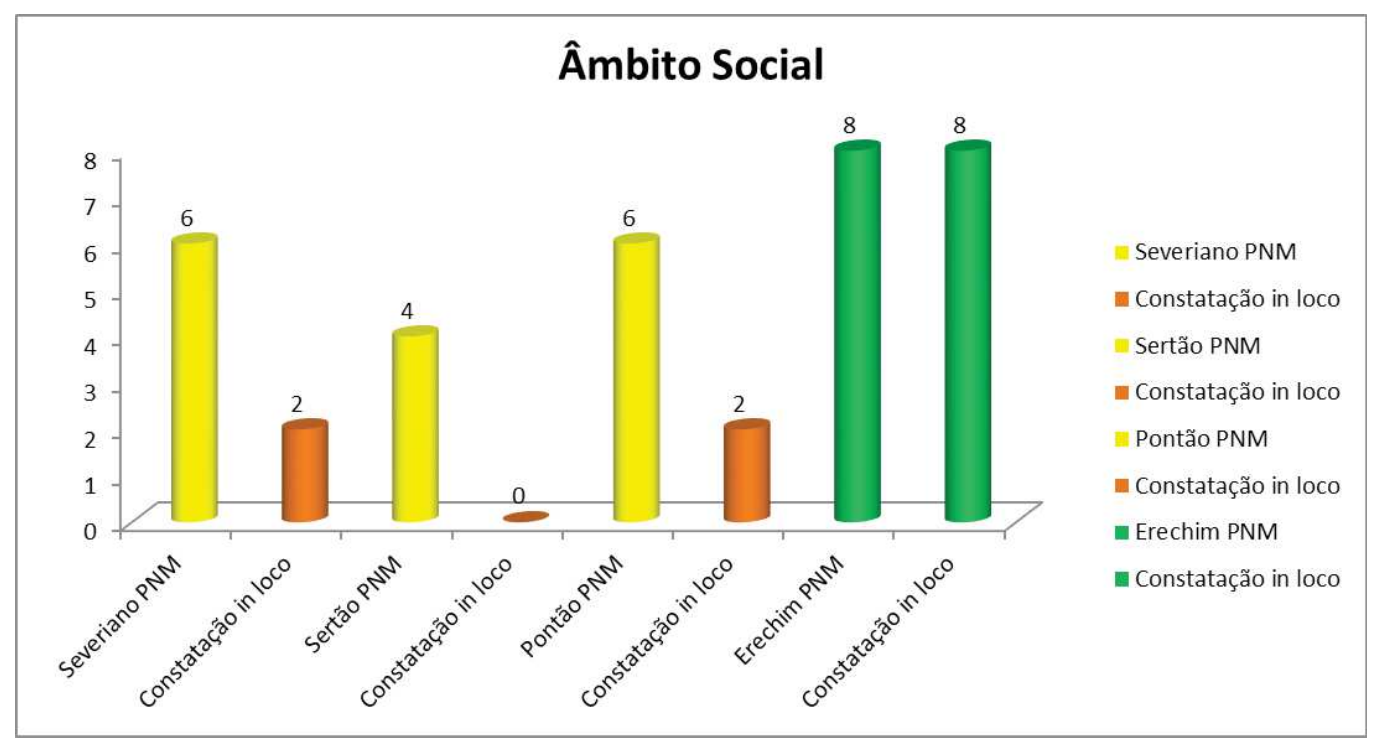

Figura 7 Gráfico demonstrativo da pontuação máxima atendida para cada PNM.

Fonte: Autores, 2014.

Na fase da avaliação social, também se constatou o atendimento das práticas para cada indicador, conforme realizado no âmbito ambiental. A análise consistiv em fotografar momentos ou detalhes pertinentes e verificar documentos como o Plano de Manejo dos PNM e restrições para o uso das áreas do entorno. A figura 8 apresenta 
as fotos com o flagrante de atendimento à comunidade da prática 9 do indicador solicitado.

Segundo o que se observa no quadro 6, apenas o PNMLM alcançou a pontuação máxima de 8,00 pontos para as práticas perguntadas, ao passo que o PNMA e o PNMDS alcançaram apenas 2,00 pontos - um parque não alcançou nenhum ponto nas práticas perguntadas.

De acordo com o que se demonstra no quadro 6 e na figura 8, pode-se perceber que o PNMS não atendeu a nenhuma prática, porque não demonstra disposição de atendimento no âmbito social.

As fotos da figura 8 demonstram a interação da comunidade com o parque, que se dá pelo atendimento das práticas solicitadas no indicador social do PNMLM. De acordo com a bióloga responsável, o local se encontra em estruturação, porém, observou-se o atendimento às práticas sociais devido ao fato de o parque localizar-se na zona urbana do município, recebendo estudantes e visitantes da cidade e da região. Por outro lado, o PNMS não atendeu a nenhuma prática social mencionada no indicador perguntado, pois se localiza na zona rural do município.
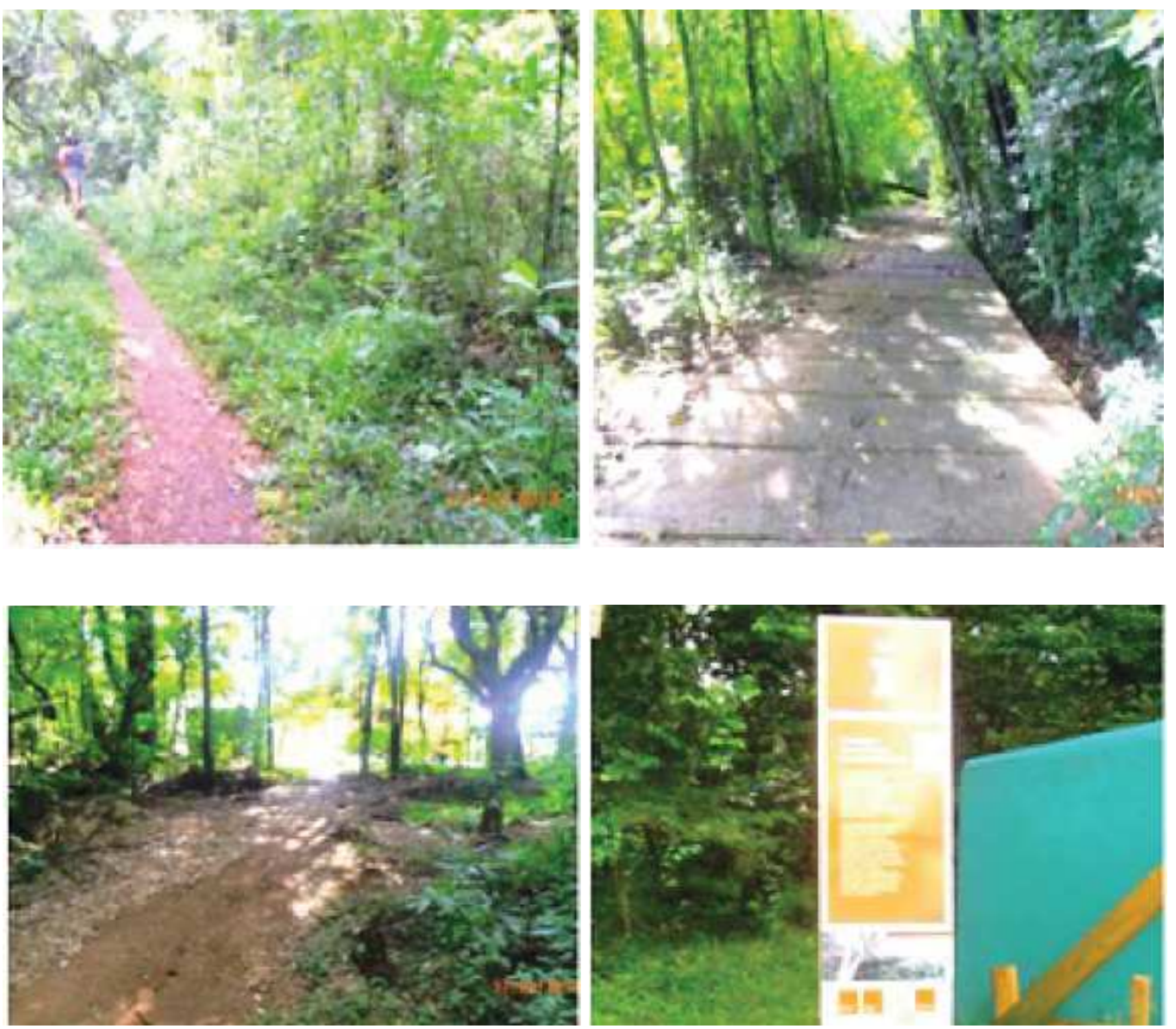

Figura 8 Fotos do PNMLM em práticas atendidas nos indicadores do âmbito social. Fonte: Autores, 2014 
Carmem Fátima Casanova, Adalberto Pandolfo, Natalia Hauenstein Eckert, Ritielli Berticelli, Naira Barbacovi, Marcele Salles Martins, Aline Pimentel Gomes

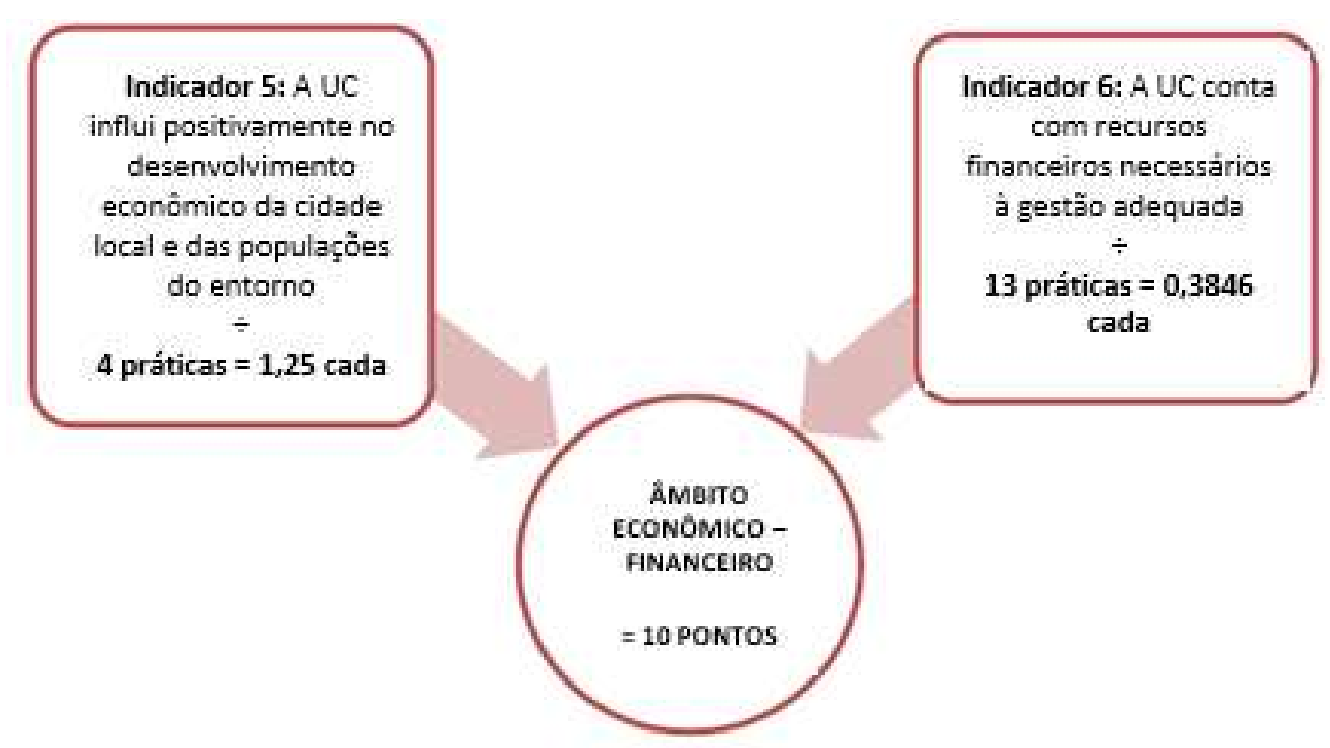

Figura 9 Esquema explicativo.

Fonte: Autores, 2014.

O PNM de Pontão e o PNM do Apertado atenderam apenas à prática 11, em que a comunidade participa das decisões do parque, mas com pouco envolvimento, por não haver efetivo controle mensal de reuniões periódicas com a comunidade. Porém, há um chamamento para que a comunidade escolar e os munícipes em geral se pronunciem sobre os parques e auxiliem na gestão compartilhada dos mesmos, segundo relato de gestores e do atendimento às práticas perguntadas.

Na avaliação do âmbito econômico-financeiro foi avaliada a visão dos gestores e a visita in loco sobre as práticas atendidas nos indicadores. A figura 9 apresenta 0 esquema explicativo sobre a identificação do âmbito econômico-financeiro.

A avaliação dos indicadores foi realizada por meio dos valores atribuídos em cada prática atendida para cada parque, gerando uma tabela de valores atendidos e não atendidos, com respectivos pesos (quadro 7). Através da visita in loco também foi possível verificar se os parques atendiam ou não às práticas questionadas.

O PNMS atendeu 4,13 pontos do máximo de 10,0 pontos divididos nos indicadores e nas práticas perguntadas. $\bigcirc$ PNMLM teve o segundo melhor resultado, com 2,78 pontos de atendimento para os 10,0 pontos da totalidade de práticas atendidas nos indicadores questionados. Segundo as respostas dos gestores, foram analisados os piores resultados que apontaram para o PNMA e o PNMS (quadro 8). A figura 10 apresenta a pontuação máxima atendida para cada PNM de acordo com os indicadores avaliados. 
Quadro 7 Avaliação no âmbito econômico-financeiro

\section{ÂMBITO ECONÔMICO-FINANCEIRO}

INDICADOR 5 - A UC influi positivamente no desenvolvimento econômico da cidade local e das populações do entorno

\begin{tabular}{|c|c|c|c|c|c|c|c|c|}
\hline Perguntas & $\begin{array}{c}\text { PNAS } \\
\text { Severiano }\end{array}$ & $\begin{array}{c}\text { Constatação } \\
\text { in loco }\end{array}$ & $\begin{array}{c}\text { PNS } \\
\text { Sertão }\end{array}$ & $\begin{array}{c}\text { Constatação } \\
\text { in loco }\end{array}$ & $\begin{array}{l}\text { PNMS } \\
\text { Pontão }\end{array}$ & $\begin{array}{c}\text { Constatação } \\
\text { in loco }\end{array}$ & \begin{tabular}{|c|} 
PNM \\
Erechim
\end{tabular} & $\begin{array}{c}\text { Constatação } \\
\text { in loco }\end{array}$ \\
\hline $\begin{array}{l}\text { P13 - As popula- } \\
\text { ções do entorno } \\
\text { e populações em } \\
\text { geral recebem } \\
\text { quais benefícios } \\
\text { diretos ou indi- } \\
\text { retos em razão } \\
\text { da existência da } \\
\text { UC? }\end{array}$ & 1,25 & 1,25 & 1,25 & 1,25 & 1,25 & 1,25 & 1,25 & 1,25 \\
\hline $\begin{array}{l}\text { P14 - A UC } \\
\text { contribui para a } \\
\text { melhoria da ren- } \\
\text { da da população } \\
\text { local? }\end{array}$ & 0,00 & 1,25 & 0,00 & 1,25 & 0,00 & 1,25 & 0,00 & 1,25 \\
\hline $\begin{array}{l}\text { P15 - A infraes- } \\
\text { trutura ou servi- } \\
\text { ços de interesse } \\
\text { da comunidade } \\
\text { local são de- } \\
\text { senvolvidos em } \\
\text { razão da UC? }\end{array}$ & 0,00 & 0,00 & 0,00 & 0,00 & 1,25 & 0,00 & 0,00 & 0,00 \\
\hline $\begin{array}{l}\text { P16 - Existem } \\
\text { projetos de de- } \\
\text { senvolvimento } \\
\text { comunitário } \\
\text { promovidos pela } \\
\text { administração da } \\
\text { UC? }\end{array}$ & 0,00 & 0,00 & 0,00 & 0,00 & 1,25 & 0,00 & 0,00 & 0,00 \\
\hline $\begin{array}{l}\text { Total de pontua- } \\
\text { ção por parque }\end{array}$ & 1,25 & 2,5 & 1,25 & 2,5 & 3,75 & 2,5 & 1,25 & 2,5 \\
\hline
\end{tabular}

INDICADOR 6 - A UC conta com recursos financeiros necessários à gestão adequada

\begin{tabular}{|c|c|c|c|c|c|c|c|c|}
\hline Perguntas & $\begin{array}{c}\text { PNAS } \\
\text { Severiano }\end{array}$ & $\begin{array}{c}\text { Constatação } \\
\text { in loco }\end{array}$ & \begin{tabular}{|c|} 
PNS \\
Sertão \\
\end{tabular} & $\begin{array}{c}\text { Constatação } \\
\text { in loco }\end{array}$ & \begin{tabular}{|l|} 
PNMS \\
Pontão \\
\end{tabular} & $\begin{array}{c}\text { Constatação } \\
\text { in loco } \\
\end{array}$ & $\begin{array}{c}\text { PNM } \\
\text { Erechim }\end{array}$ & $\begin{array}{c}\text { Constatação } \\
\text { in loco }\end{array}$ \\
\hline $\begin{array}{l}\text { P17 - Há custos } \\
\text { reais da manu- } \\
\text { tenção da UC? }\end{array}$ & 0,00 & 0,00 & 0,00 & 0,00 & 0,00 & 0,00 & 0,00 & 0,00 \\
\hline $\begin{array}{l}\text { P18 - Há receitas } \\
\text { e despesas? }\end{array}$ & 0,00 & 0,00 & 0,00 & 0,00 & 0,00 & 0,00 & 0,3846 & 0,3846 \\
\hline $\begin{array}{l}\text { P19 - Há fontes } \\
\text { diversas de valo- } \\
\text { res recebidos? }\end{array}$ & 0,00 & 0,3846 & 0,00 & 0,3846 & 0,00 & 0,3846 & 0,00 & 0,3846 \\
\hline $\begin{array}{l}\text { P20 - Há receitas } \\
\text { e cobrem os cus- } \\
\text { tos de manuten- } \\
\text { ção da UC? }\end{array}$ & 0,00 & 0,00 & 0,00 & 0,00 & 0,00 & 0,00 & 0,3846 & 0,3846 \\
\hline
\end{tabular}


Carmem Fátima Casanova, Adalberto Pandolfo, Natalia Hauenstein Eckert, Ritielli Berticelli, Naira Barbacovi, Marcele Salles Martins, Aline Pimentel Gomes

\begin{tabular}{l|l|l|l|l|l|l|l|l}
\hline $\begin{array}{l}\text { P21 - Há fontes } \\
\text { de financiamento } \\
\text { e são adequadas } \\
\text { e diversas para } \\
\text { a manutenção } \\
\text { da UC em longo } \\
\text { prazo? }\end{array}$ & 0,00 & 0,00 & 0,00 & 0,00 & 0,00 & 0,00 & 0,00 & 0,00 \\
\hline
\end{tabular}

INDICADOR 6 - A UC conta com recursos financeiros necessários à gestão adequada

\begin{tabular}{|c|c|c|c|c|c|c|c|c|}
\hline Perguntas & $\begin{array}{c}\text { PNAS } \\
\text { Severiano }\end{array}$ & $\begin{array}{c}\text { Constatação } \\
\text { in loco }\end{array}$ & $\begin{array}{c}\text { PNS } \\
\text { Sertão }\end{array}$ & $\begin{array}{c}\text { Constatação } \\
\text { in loco }\end{array}$ & $\begin{array}{l}\text { PNMS } \\
\text { Pontão }\end{array}$ & $\begin{array}{c}\text { Constatação } \\
\text { in loco }\end{array}$ & $\begin{array}{c}\text { PNM } \\
\text { Erechim }\end{array}$ & $\begin{array}{c}\text { Constatação } \\
\text { in loco }\end{array}$ \\
\hline $\begin{array}{l}\text { P22 - Possui } \\
\text { estratégias para } \\
\text { obter recursos } \\
\text { financeiros sufi- } \\
\text { cientes e diver- } \\
\text { sos? }\end{array}$ & 0,00 & 0,00 & 0,00 & 0,00 & 0,3846 & 0,00 & 0,3846 & 0,00 \\
\hline $\begin{array}{l}\text { P23 - Possui } \\
\text { vendas de bens } \\
\text { e serviços aos } \\
\text { usuários diretos } \\
\text { da UC? }\end{array}$ & 0,00 & 0,00 & 0,00 & 0,00 & 0,00 & 0,00 & 0,00 & 0,00 \\
\hline $\begin{array}{l}\text { P24 - Possui } \\
\text { venda de serviços } \\
\text { ambientais? }\end{array}$ & 0,00 & 0,00 & 0,00 & 0,00 & 0,00 & 0,00 & 0,3846 & 0,00 \\
\hline $\begin{array}{l}\text { P25 - Ocorre } \\
\text { manejo financei- } \\
\text { ro institucional? }\end{array}$ & 0,00 & 0,00 & 0,00 & 0,00 & 0,00 & 0,00 & 0,00 & 0,00 \\
\hline $\begin{array}{l}\text { P26 - Como base } \\
\text { de uma gestão } \\
\text { adequada, quais } \\
\text { os mecanismos } \\
\text { de gestão finan- } \\
\text { ceira eficientes? }\end{array}$ & 0,00 & 0,00 & 0,00 & 0,00 & 0,00 & 0,00 & 0,00 & 0,00 \\
\hline $\begin{array}{l}\text { P27 - Ocorre } \\
\text { transferência de } \\
\text { recursos financei- } \\
\text { ros ajustados ao } \\
\text { que é solicitado? }\end{array}$ & 0,00 & 0,00 & 0,00 & 0,00 & 0,00 & 0,00 & 0,00 & 0,00 \\
\hline $\begin{array}{l}\text { P28 - Os recur- } \\
\text { sos gerados são } \\
\text { aplicados na me- } \\
\text { lhoria da gestão } \\
\text { ou no plano de } \\
\text { manejo da UC? }\end{array}$ & 0,00 & 0,00 & 0,00 & 0,00 & 0,00 & 0,00 & 0,00 & 0,00 \\
\hline $\begin{array}{l}\text { P29 - Quais são } \\
\text { os mecanismos } \\
\text { de controle e } \\
\text { auditoria à ges- } \\
\text { tão financeira } \\
\text { adequada? }\end{array}$ & 0,00 & 0,00 & 0,00 & 0,00 & 0,00 & 0,00 & 0,00 & 0,00 \\
\hline $\begin{array}{l}\text { Total de pontua- } \\
\text { ção por parque }\end{array}$ & 0,00 & 0,3846 & 0,00 & 0,3846 & 0,3846 & 0,3846 & 1,1538 & 1,1538 \\
\hline $\begin{array}{l}\text { Total de pontu- } \\
\text { ação em cada } \\
\text { município }\end{array}$ & 1,25 & 1,6346 & 1,25 & 2,8846 & 4,1346 & 2,8846 & 2,7884 & 3,6538 \\
\hline
\end{tabular}

Fonte: Autores, 2014. 


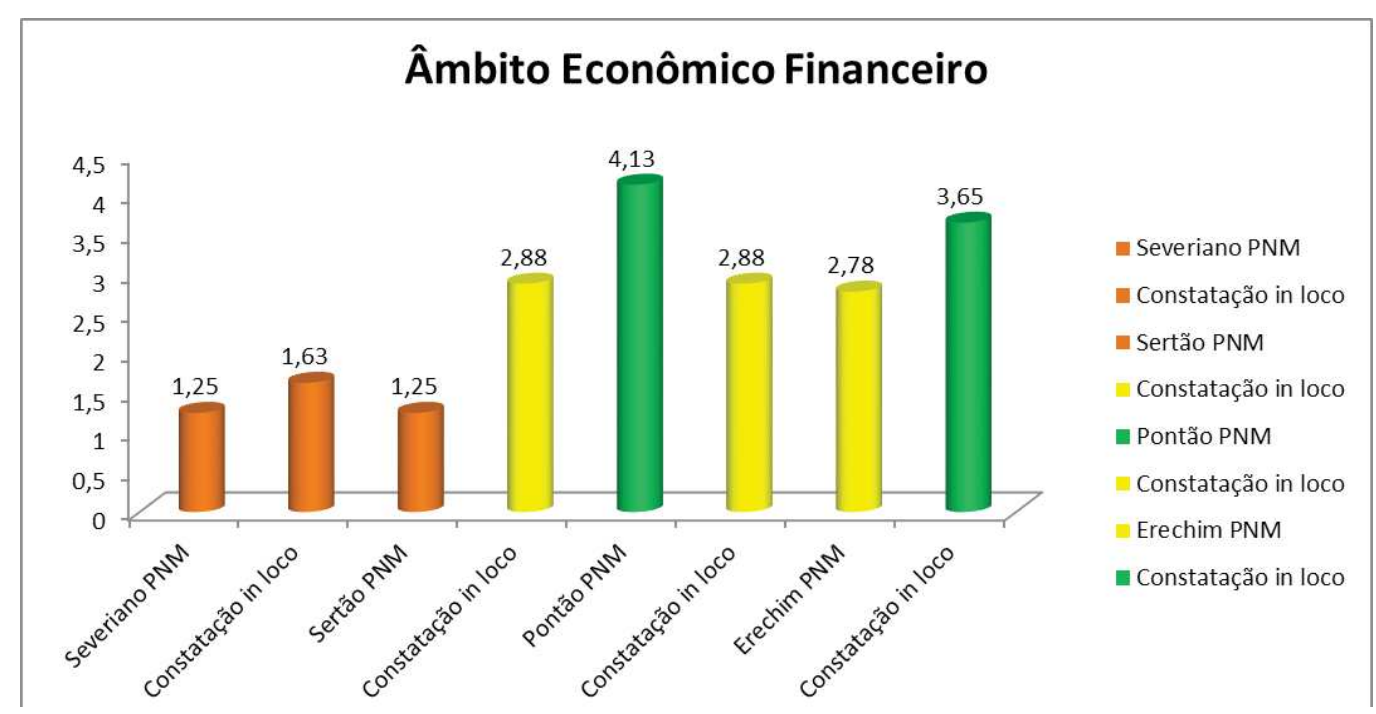

Figura 10 Gráfico demonstrativo da pontuação máxima atendida para cada PNM.

Fonte: Autores, 2014.

As melhorias e investimentos devem e estão sendo feitas no PNMLM de Erechim, pois se percebeu que não há acumulo de resíduos nas trilhas e há informação aos que passam pelo parque de que ali está uma UC. $O$ relato do gestor informou que há previsão de $\mathrm{R} \$ 500.000,00$ para o atendimento das práticas ambientais, sociais, econômicas e institucionais, trazidas no estudo do Plano de Manejo.

Em relação à visita, apenas um parque teve pontuação máxima de 3,65 pontos, - PNMLM de Erechim; dois parques, o PNMDS em Sertão e o PNMS em Pontão, tiveram 2,88 pontos (de no máximo 10,0 pontos). O PNMDS demonstrou maior cuidado com as atividades de investimentos, principalmente investindo na visualização da área, porém, em relação ao Plano de Manejo, observa-se o abandono do local, inclusive em relação à participação dos alunos nas atividades práticas das aulas de educação ambiental.

A figura 11 apresenta os registros fotográficos da visita in loco ao PNMLM de Erechim. Os investimentos estão voltados para a infraestrutura e o atendimento ao público em geral, apesar de o plano de manejo ter sido realizado há dois anos.

O PNMLM possui Plano de Manejo datado de 2011, sendo executado em 2014. O gestor e a bióloga responsável relataram, durante a visita in loco, a retirada das árvores exóticas e a pavimentação das trilhas, assim como o cercamento e as calçadas para os atletas aproveitarem o espaço. Apesar de o Parque estar inserido em uma área urbana, trata-se de local com ar puro e grandes possibilidades de tornar-se muito visitado nos próximos anos. A gestão atual relatou que, após o investimento, o PNMLM estará pronto para receber as pessoas, tornando-se uma referência de parques de proteção de uso integral em Erechim e região. Na avaliação no âmbito institucional, observou-se a visão dos gestores sobre as práticas atendidas, segundo o questionário e a visita in loco. A figura 12 apresenta o esquema explicativo sobre a identificação do âmbito institucional. 

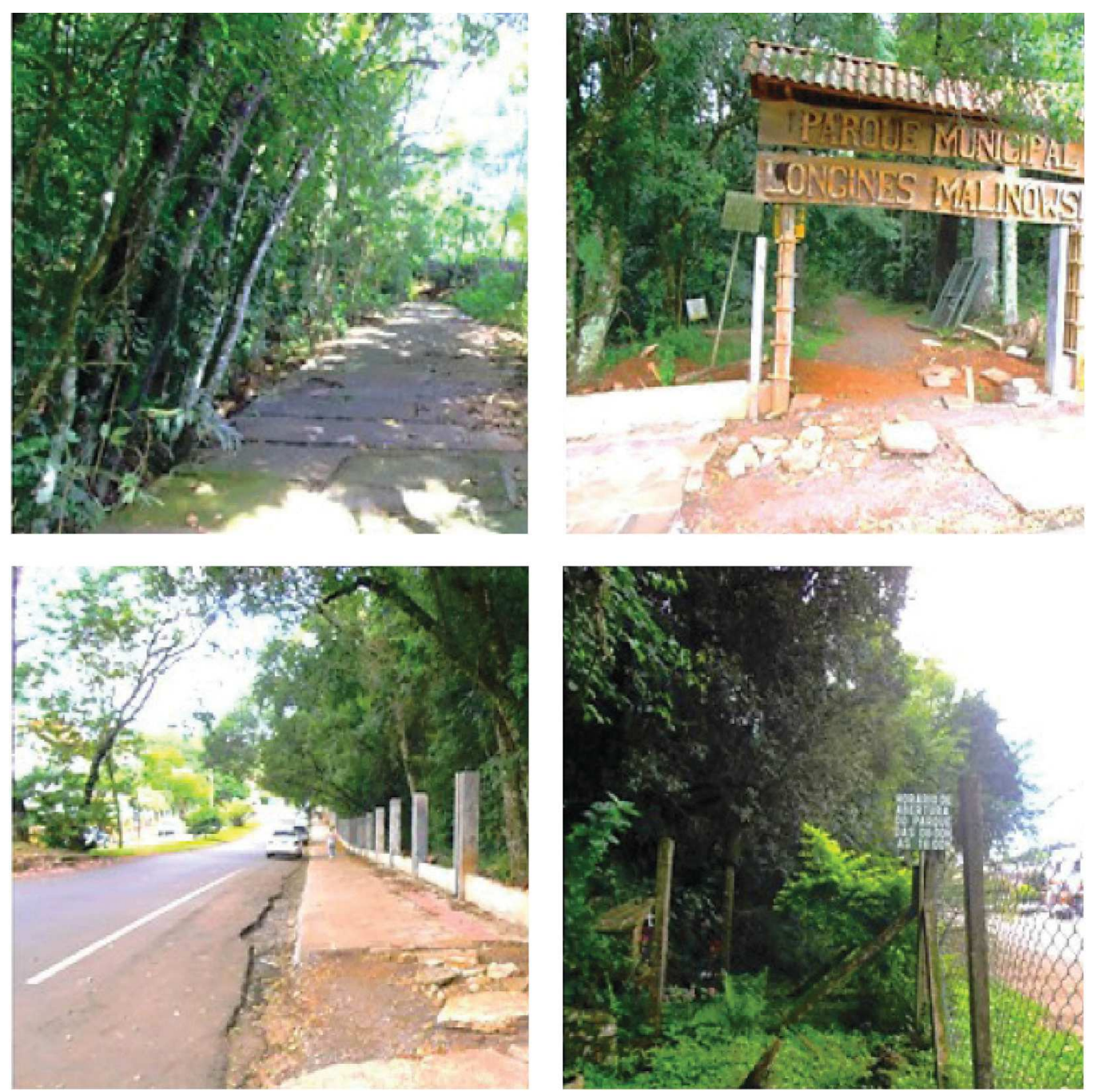

Figura 11 Fotos do PNMLM em práticas atendidas nos indicadores do âmbito econômico-financeiro. Fonte: Autores, 2014.

Segundo as respostas dos gestores (quadro 9), o PNMLM atendeu 5,11 pontos do máximo de 10,0 pontos divididos nos indicadores das práticas perguntadas. Já o PNMA teve o segundo melhor resultado, com 4,11 pontos de atendimento para os 10,0 pontos da totalidade de práticas questionadas. Os resultados considerados negativos no âmbito institucional ficaram com o PNMS e o PNMDS, onde poucas das práticas questionadas foram atendidas. $O$ quadro 8 apresenta os indicadores e práticas avaliados no âmbito institucional. 
Figura 12 Esquema explicativo.

Fonte: Autores, 2014.

Quadro 8 Avaliação no âmbito institucional

\section{INDICADOR INSTITUCIONAL}

\begin{tabular}{|c|c|c|c|c|c|c|c|c|}
\hline Perguntas & $\begin{array}{c}\text { PNAS } \\
\text { Severiano }\end{array}$ & $\begin{array}{c}\text { Constatação } \\
\text { in loco }\end{array}$ & $\begin{array}{l}\text { PNS } \\
\text { Sertão }\end{array}$ & $\begin{array}{c}\text { Constatação } \\
\text { in loco }\end{array}$ & $\begin{array}{l}\text { PNMS } \\
\text { Pontão }\end{array}$ & $\begin{array}{c}\text { Constatação } \\
\text { in loco }\end{array}$ & $\begin{array}{c}\text { PNM } \\
\text { Erechim }\end{array}$ & $\begin{array}{c}\text { Constatação } \\
\text { in loco }\end{array}$ \\
\hline $\begin{array}{l}\text { P30 - Ocorre um } \\
\text { planejamento } \\
\text { estratégico da } \\
\text { UC que está } \\
\text { relacionado } \\
\text { com as políticas } \\
\text { estabelecidas para } \\
\text { o sistema de UC? }\end{array}$ & 0,2380 & 0,00 & 0,238 & 0,00 & 0,00 & 0,00 & 0,2380 & 0,2380 \\
\hline $\begin{array}{l}\text { P31 - Há coerência } \\
\text { entre os planos } \\
\text { e projetos } \\
\text { necessários ao } \\
\text { plano de manejo? }\end{array}$ & 0,2380 & 0,00 & 0,00 & 0,00 & 0,2380 & 0,00 & 0,2380 & 0,2380 \\
\hline $\begin{array}{l}\text { P32 - Ocorrem } \\
\text { monitoramento } \\
\text { e avaliação dos } \\
\text { ajustes a serem } \\
\text { realizados ao longo } \\
\text { do tempo? }\end{array}$ & 0,00 & 0,00 & 0,00 & 0,00 & 0,00 & 0,00 & 0,2380 & 0,2380 \\
\hline $\begin{array}{l}\text { P33 - Existe na } \\
\text { atualidade plano } \\
\text { de manejo? }\end{array}$ & 0,00 & 0,00 & 0,00 & 0,00 & 0,2380 & 0,2380 & 0,2380 & 0,2380 \\
\hline $\begin{array}{l}\text { P34 - O plano de } \\
\text { manejo considera } \\
\text { as iniciativas de } \\
\text { desenvolvimento } \\
\text { local ou regional? }\end{array}$ & 0,00 & 0,00 & 0,00 & 0,00 & 0,00 & 0,2380 & 0,2380 & 0,2380 \\
\hline
\end{tabular}


Carmem Fátima Casanova, Adalberto Pandolfo, Natalia Hauenstein Eckert, Ritielli Berticelli, Naira Barbacovi, Marcele Salles Martins, Aline Pimentel Gomes

\begin{tabular}{l|c|c|c|c|c|c|c|c}
\hline $\begin{array}{l}\text { P35 - Existe } \\
\text { execução dos } \\
\text { programas de } \\
\text { manejo? }\end{array}$ & 0,00 & 0,00 & 0,00 & 0,00 & 0,00 & 0,00 & 0,2380 & 0,2380 \\
\hline $\begin{array}{l}\text { Total de pontos por } \\
\text { indicador }\end{array}$ & 0,476 & 0,00 & 0,238 & 0,00 & 0,476 & 0,476 & 1,428 & 1,428 \\
\hline
\end{tabular}

Indicador 8 - Pessoal ou humano qualificado e suficiente para o desempenho das atividades de gerenciamento do local

\begin{tabular}{c|c|c|c|c|c|c|c|c}
\hline \multicolumn{1}{c|}{ Perguntas } & $\begin{array}{c}\text { PNAS } \\
\text { Severiano }\end{array}$ & $\begin{array}{c}\text { Constatação } \\
\text { in loco }\end{array}$ & $\begin{array}{c}\text { PNS } \\
\text { Sertão }\end{array}$ & $\begin{array}{c}\text { Constatação } \\
\text { in loco }\end{array}$ & $\begin{array}{c}\text { PNMS } \\
\text { Pontão }\end{array}$ & $\begin{array}{c}\text { Constatação } \\
\text { in loco }\end{array}$ & $\begin{array}{c}\text { PNM } \\
\text { Erechim }\end{array}$ & $\begin{array}{c}\text { Constatação } \\
\text { in loco }\end{array}$ \\
\hline $\begin{array}{l}\text { P36-A quantidade de } \\
\text { pessoal é suficiente? }\end{array}$ & 0,00 & 0,7142 & 0,00 & 0,7142 & 0,00 & 0,7142 & 0,00 & 0,7142 \\
\hline $\begin{array}{l}\text { P37-A qualidade de } \\
\text { demanda pessoal é } \\
\text { suficiente? }\end{array}$ & 0,00 & 0,00 & 0,00 & 0,00 & 0,00 & 0,00 & 0,00 & 0,7142 \\
\hline $\begin{array}{l}\text { Total de pontos por } \\
\text { indicador }\end{array}$ & 0,00 & 0,7142 & 0,00 & 0,7142 & 0,00 & 0,7142 & 0,00 & 1,4284 \\
\hline
\end{tabular}

\begin{tabular}{l|c|c|c|c|c|c|c|c}
\hline \multicolumn{7}{c}{ Indicador 9 - A área oferece condições adequadas de trabalho } \\
\hline Perguntas & $\begin{array}{c}\text { PNAS } \\
\text { Severiano }\end{array}$ & $\begin{array}{c}\text { Constatação } \\
\text { in loco }\end{array}$ & $\begin{array}{c}\text { PNS } \\
\text { Sertão }\end{array}$ & $\begin{array}{c}\text { Constatação } \\
\text { in loco }\end{array}$ & $\begin{array}{c}\text { PNMS } \\
\text { Pontão }\end{array}$ & $\begin{array}{c}\text { Constatação } \\
\text { in loco }\end{array}$ & $\begin{array}{c}\text { PNM } \\
\text { Erechim }\end{array}$ & $\begin{array}{c}\text { Constatação } \\
\text { in loco }\end{array}$ \\
\hline $\begin{array}{l}\text { P38- Existem } \\
\text { condições de higiene } \\
\text { e segurança? }\end{array}$ & 0,00 & 0,00 & 0,00 & 0,00 & 0,7142 & 0,00 & 0,7142 & 0,00 \\
\hline $\begin{array}{l}\text { P39-Salários e } \\
\text { benefícios pagos aos } \\
\text { funcionários estão de } \\
\text { acordo? }\end{array}$ & 0,00 & 0,00 & 0,00 & 0,7142 & 0,00 & 0,7142 & 0,00 & 0,7142 \\
\hline $\begin{array}{l}\text { Total de pontos por } \\
\text { indicador }\end{array}$ & 0,00 & 0,00 & 0,00 & 0,7142 & 0,7142 & 0,7142 & 0,7142 & 0,7142 \\
\hline
\end{tabular}

Indicador 10 - Quanto à estrutura e infraestrutura (equipamentos existentes), satisfazerem as necessidades de manejo da UC

\begin{tabular}{l|c|c|c|c|c|c|c|c}
\hline $\begin{array}{l}\text { P40 - Existe uma } \\
\text { estrutura que } \\
\text { corresponda aos } \\
\text { objetivos de criação } \\
\text { do parque? }\end{array}$ & 0,3571 & 0,00 & 0,00 & 0,00 & 0,00 & 0,3571 & 0,3571 & 0,3571 \\
\hline $\begin{array}{l}\text { P41 - Existe infra- } \\
\text { estrutura e se esta é } \\
\text { adequada? }\end{array}$ & 0,00 & 0,00 & 0,00 & 0,00 & 0,3571 & 0,3571 & 0,3571 & 0,3571 \\
\hline $\begin{array}{l}\text { P42 - Existem } \\
\text { acessos e estes são } \\
\text { adequados para } \\
\text { alcançar os objetivos } \\
\text { do Parque? }\end{array}$ & 0,3571 & 0,3571 & 0,00 & 0,3571 & 0,00 & 0,3571 & 0,00 & 0,3571 \\
\hline $\begin{array}{l}\text { Total de pontos por } \\
\text { indicador }\end{array}$ & 0,7142 & 0,3571 & 0,00 & 0,3571 & 0,3571 & 1,0713 & 1,0713 & 1,0713 \\
\hline
\end{tabular}

Indicador 11 - Quanto à legislação, normas, técnicas e disposições administrativas

\begin{tabular}{l|c|c|c|c|c|c|c|c}
\hline $\begin{array}{l}\text { P43 - A administração } \\
\text { possui apoio para a } \\
\text { gestão da UC? }\end{array}$ & 0,000 & 0,00 & 0,00 & 0,00 & 0,00 & 0,00 & 0,2040 & 0,2040 \\
\hline
\end{tabular}




\begin{tabular}{l|c|c|c|c|c|c|c|c}
\hline $\begin{array}{l}\text { P44 - Existem } \\
\text { equipamentos e } \\
\text { ferramentas para o } \\
\text { trabalho e estes são } \\
\text { suficientes? }\end{array}$ & 0,2040 & 0,00 & 0,204 & 0,00 & 0,2040 & 0,00 & 0,2040 & 0,2040 \\
\hline $\begin{array}{l}\text { P45 - Possui status } \\
\text { legal de criação da } \\
\text { área? }\end{array}$ & 0,2040 & 0,2040 & 0,204 & 0,2040 & 0,2040 & 0,2040 & 0,2040 & 0,2040 \\
\hline $\begin{array}{l}\text { P46 - Possui } \\
\text { regulamento de } \\
\text { uso dos recursos } \\
\text { naturais? }\end{array}$ & 0,2040 & 0,00 & 0,00 & 0,00 & 0,2040 & 0,00 & 0,2040 & 0,2040 \\
\hline $\begin{array}{l}\text { P47 - Este } \\
\text { regulamento também } \\
\text { prevê uma gestão } \\
\text { financeira? }\end{array}$ & 0,00 & 0,00 & 0,00 & 0,00 & 0,00 & 0,00 & 0,2040 & 0,2040 \\
\hline $\begin{array}{l}\text { P48 - Existe um } \\
\text { regulamento } \\
\text { administrativo? }\end{array}$ & 0,2040 & 0,2040 & 0,00 & 0,2040 & 0,00 & 0,2040 & 0,2040 & 0,2040 \\
\hline $\begin{array}{l}\text { P49 - Existem leis } \\
\text { relacionadas ao } \\
\text { planejamento, } \\
\text { manejo e gestão do } \\
\text { parque? }\end{array}$ & 0,2040 & 0,2040 & 0,204 & 0,2040 & 0,2040 & 0,2040 & 0,2040 & 0,2040 \\
\hline $\begin{array}{l}\text { Total alcançado por } \\
\text { indicador }\end{array}$ & 1,02 & 0,612 & 0,612 & 0,612 & 0,612 & 0,612 & 1,428 & 1,428 \\
\hline
\end{tabular}

Indicador 12 - Quanto aos mecanismos de solução, conflitos relacionados ao domínio, posse de terras e uso de recursos naturais, se são efetivos

\begin{tabular}{|c|c|c|c|c|c|c|c|c|}
\hline Perguntas & $\begin{array}{c}\text { PNAS } \\
\text { Severiano }\end{array}$ & \begin{tabular}{|c} 
Constatação \\
in loco
\end{tabular} & $\begin{array}{c}\text { PNS } \\
\text { Sertão }\end{array}$ & \begin{tabular}{|c|c|}
$\begin{array}{c}\text { Constatação } \\
\text { in loco }\end{array}$ \\
\end{tabular} & \begin{tabular}{|l} 
PNMS \\
Pontão \\
\end{tabular} & $\begin{array}{c}\text { Constatação } \\
\text { in loco }\end{array}$ & $\begin{array}{c}\text { PNM } \\
\text { Erechim }\end{array}$ & $\begin{array}{c}\text { Constatação } \\
\text { in loco }\end{array}$ \\
\hline $\begin{array}{l}\text { P50 - São } \\
\text { usadas } \\
\text { estratégias } \\
\text { para a } \\
\text { resolução } \\
\text { de conflitos } \\
\text { relacionados } \\
\text { com o domínio } \\
\text { legal das } \\
\text { terras? }\end{array}$ & 0,7142 & 0,00 & 0,714 & 0,00 & 0,00 & 0,7142 & 0,00 & 0,00 \\
\hline $\begin{array}{l}\text { P51 - São } \\
\text { usadas } \\
\text { estratégias } \\
\text { para resolução } \\
\text { de conflitos } \\
\text { relacionados } \\
\text { ao uso dos } \\
\text { recursos da } \\
\text { UC? }\end{array}$ & 0,7142 & 0,00 & 0,714 & 0,00 & 0,00 & 0,00 & 0,00 & 0,00 \\
\hline $\begin{array}{l}\text { Total de pontos } \\
\text { por indicador }\end{array}$ & 1,4284 & 0,00 & 1,428 & 0,00 & 0,00 & 0,7142 & 0,00 & 0,00 \\
\hline
\end{tabular}

Indicador 13 - Quanto à área, se conta com estrutura organizativa adequada ao manejo

\begin{tabular}{l|c|c|c|c|c|c|c|c}
\hline Perguntas & $\begin{array}{c}\text { PNAS } \\
\text { Severiano }\end{array}$ & $\begin{array}{c}\text { Constatação } \\
\text { in loco }\end{array}$ & $\begin{array}{c}\text { PNS } \\
\text { Sertão }\end{array}$ & $\begin{array}{c}\text { Constatação } \\
\text { in loco }\end{array}$ & $\begin{array}{c}\text { PNMS } \\
\text { Pontão }\end{array}$ & $\begin{array}{c}\text { Constatação } \\
\text { in loco }\end{array}$ & $\begin{array}{c}\text { PNM } \\
\text { Erechim }\end{array}$ & $\begin{array}{c}\text { Constatação } \\
\text { in loco }\end{array}$ \\
\hline $\begin{array}{l}\text { P52 - Possui } \\
\text { estrutura } \\
\text { organizacional? }\end{array}$ & 0,4761 & 0,00 & 0,476 & 0,00 & 0,00 & 0,00 & 0,4761 & 0,4761 \\
\hline
\end{tabular}


Carmem Fátima Casanova, Adalberto Pandolfo, Natalia Hauenstein Eckert, Ritielli Berticelli, Naira Barbacovi, Marcele Salles Martins, Aline Pimentel Gomes

\begin{tabular}{l|c|c|c|c|c|c|c|c}
\hline $\begin{array}{l}\text { P53 - Possui } \\
\text { sistema } \\
\text { funcional de } \\
\text { comunicação } \\
\text { interna? }\end{array}$ & 0,4761 & 0,00 & 0,476 & 0,00 & 0,00 & 0,00 & 0,00 & 0,00 \\
\hline $\begin{array}{l}\text { P54 - Possui } \\
\text { mecanismos } \\
\text { de registro de } \\
\text { ações para a } \\
\text { informação da } \\
\text { gestão da UC? }\end{array}$ & 0,00 & 0,00 & 0,476 & 0,00 & 0,00 & 0,00 & 0,00 & 0,00 \\
\hline $\begin{array}{l}\text { Total de pontos } \\
\text { por indicador }\end{array}$ & 0,9522 & 0,00 & 1,428 & 0,00 & 0,00 & 0,00 & 0,4761 & 0,4761 \\
\hline $\begin{array}{l}\text { Total de } \\
\text { pontuação }\end{array}$ & 4,1148 & 1,6833 & 3,706 & 3,1117 & 2,3633 & 4,3297 & 5,1176 & 6,546 \\
\hline
\end{tabular}

Fonte: Autores, 2014.

A figura 13 apresenta a pontuação máxima atendida para cada PNM, de acordo com os indicadores.

Após análises, observou-se que os parques PNMLM e PNMDS possuem Planos de Manejo, mesmo que obsoletos. Ainda assim os dois apresentaram mais cumprimento em suas práticas dos indicadores perguntados no âmbito institucional. Já o PNMA e o PNMS, ficaram empatados por não realizarem tantas práticas institucionais questionadas. Na visita verificou-se o atendimento das práticas para cada indicador no âmbito institucional. A análise consistiu em fotografar momentos ou detalhes pertinentes e verificar documentos e relatos dos gestores. A figura 14, com fotos de partes específicas do parque, em sua integridade física, apresenta os diversos aspectos naturais observados no PNMA e mostra que alguns locais apresentam regeneração natural de queimadas, no entanto, por tratar-se de um PNM, de proteção integral, o resguardo do habitat natural deve ser o maior possível.

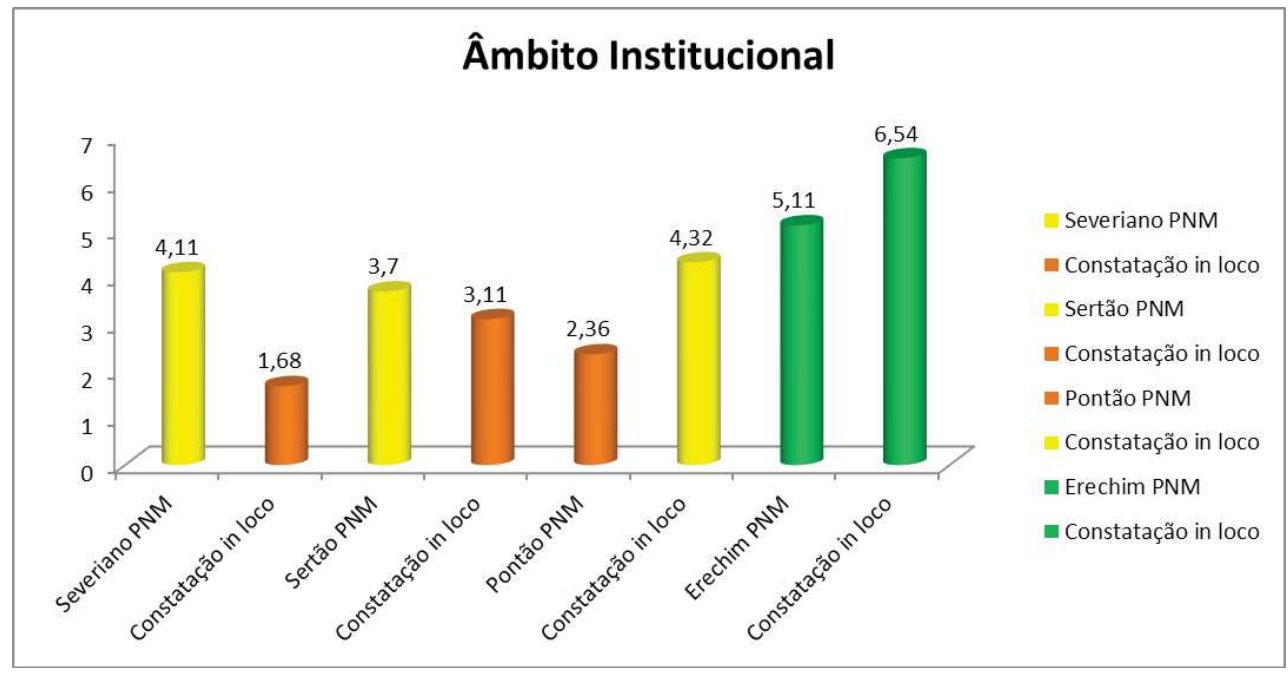

Figura 13 Gráfico demonstrativo da pontuação máxima atendida para cada PNM. Fonte: Autores, 2014. 

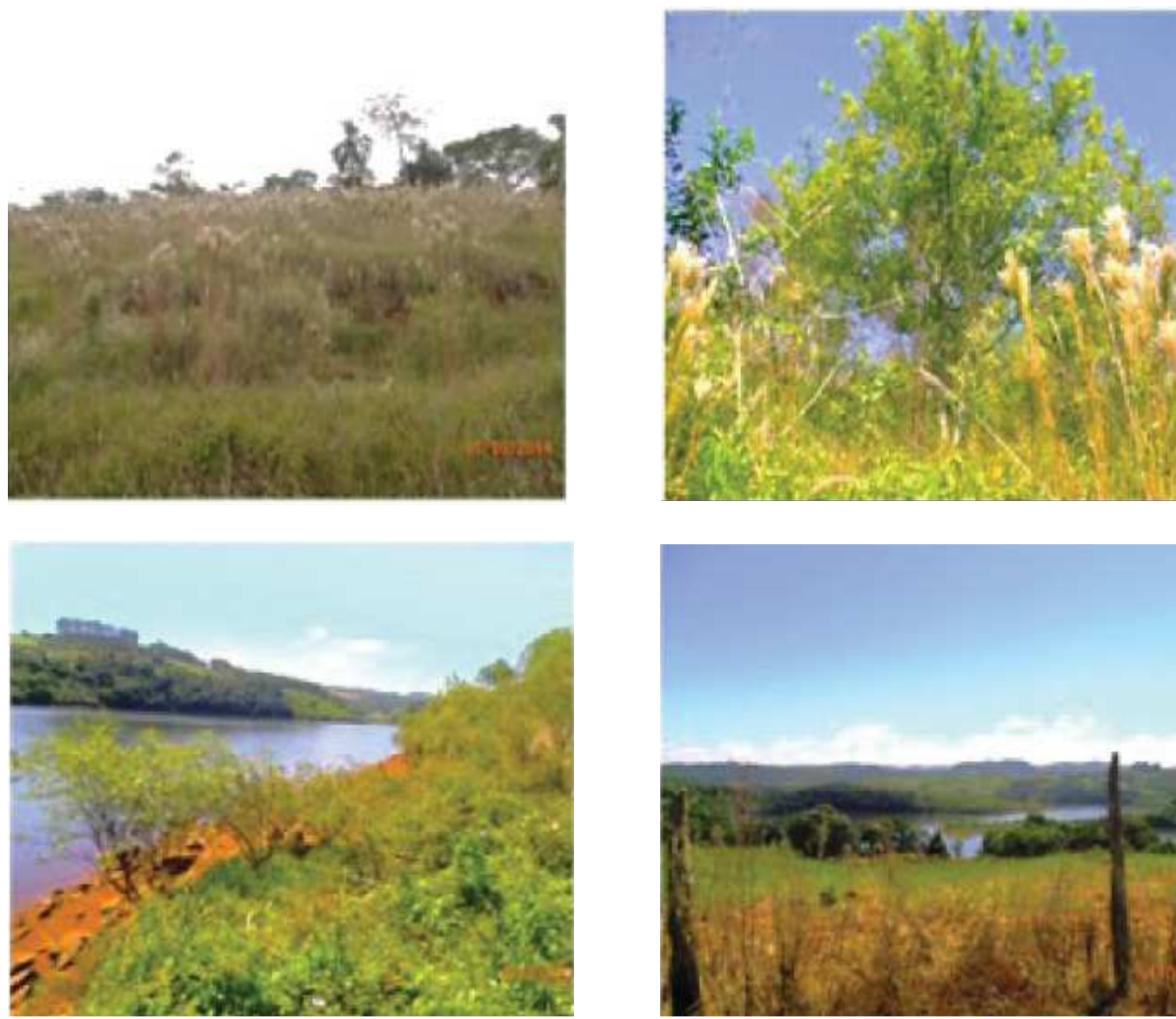

Figura 14 Fotos do PNMA em práticas atendidas nos indicadores do âmbito institucional. Fonte: Autores, 2014.

Constatou-se também que o parque não possui Plano de Manejo, o que o torna vulnerável no seu gerenciamento, assim como as restrições de uso. Segundo relato do diretor do PNMA e a realização da visita in loco, alguns lugares sofreram queimadas, no entanto, há evidência de concentração de caça e pesca. $\bigcirc$ gestor informou que a todo o momento acontecem problemas relacionados aos lindeiros e que a comunidade não vê a importância da preservação do local. A avaliação dos resultados obtidos em todos os parques, nos diferentes âmbitos avaliados, é apresentada no quadro 9.

Com relação às respostas dos gestores, os melhores resultados foram observados no PNMS e no PNMLM, com 8,33 pontos no âmbito ambiental. No âmbito social o melhor resultado foi no PNMLM, com 8,00 pontos para todos os indicadores avaliados. Já no âmbito econômico-financeiro, o melhor resultado ficou para o PNMDS, com 4,13 pontos. No âmbito institucional o PNMLM de Erechim se destacou - pontuando 5,11 -, obtendo a pontuação máxima geral com 24,22 pontos. Observa-se no quadro 10 o resultado geral na pontuação obtida em observação in loco. 
Carmem Fátima Casanova, Adalberto Pandolfo, Natalia Hauenstein Eckert, Ritielli Berticelli, Naira Barbacovi, Marcele Salles Martins, Aline Pimentel Gomes

Quadro 9 Pontuação geral obtida segundo respostas dos gestores

\begin{tabular}{c|c|c|c|c}
\hline \multicolumn{5}{c}{ Pontuação obtida de acordo com as respostas dos gestores } \\
\hline \multirow{4}{*}{$\hat{\text { AMMBITO }}$} & $\begin{array}{c}\text { PNMS } \\
\text { Sertão }\end{array}$ & $\begin{array}{c}\text { PNMS } \\
\text { Sagrisa }\end{array}$ & $\begin{array}{c}\text { PNMA Severiano } \\
\text { de Almeida }\end{array}$ & $\begin{array}{c}\text { PNMLM } \\
\text { Erechim }\end{array}$ \\
\hline Ambiental & $8,33^{*}$ & 6,11 & 6,66 & $8,33^{*}$ \\
\hline Social & 6,00 & 4,00 & 6,00 & $8,00^{*}$ \\
\hline $\begin{array}{c}\text { Econômico- } \\
\text { Financeiro }\end{array}$ & 1,25 & $4,13^{*}$ & 1,25 & 2,78 \\
\hline Institucional & 3,7 & 2,36 & 4,11 & $5,11^{*}$ \\
\hline Pontuação geral & 19,28 & 16,60 & 18,02 & $24,22^{*}$ \\
\hline \multicolumn{5}{c}{ Máximo de pontuação geral 40,00} \\
\hline
\end{tabular}

Fonte: Autores, 2014.

Quadro 10 Pontuação geral obtida segundo observação in loco

\begin{tabular}{c|c|c|c|c}
\hline \multicolumn{5}{c}{ Pontuação obtida segundo observação in loco } \\
\hline \multirow{5}{*}{ ÂMBITO } & $\begin{array}{c}\text { PNMS } \\
\text { Sertão }\end{array}$ & $\begin{array}{c}\text { PNMDS } \\
\text { Sagrisa }\end{array}$ & $\begin{array}{c}\text { PNMA Severiano de } \\
\text { Almeida }\end{array}$ & $\begin{array}{c}\text { PNMLM } \\
\text { Erechim }\end{array}$ \\
\hline Ambiental & 6,66 & $8,33^{*}$ & 1,68 & $8,33^{*}$ \\
\hline Social & 2,00 & 0,00 & 2,00 & $8,00^{*}$ \\
\hline $\begin{array}{c}\text { Econômico- } \\
\text { Financeiro }\end{array}$ & 2,88 & 2,88 & 1,68 & $3,65^{*}$ \\
\hline Institucional & 3,11 & 4,32 & 1,68 & $6,54^{*}$ \\
\hline Pontuação geral & 14,65 & 15,53 & 7,04 & $26,52^{*}$ \\
\hline \multicolumn{5}{c}{$\begin{array}{c}\text { Máximo de pontuação geral } 40,00 \\
\text { Mínimo de pontuação geral } 0,00\end{array}$} \\
\hline
\end{tabular}

Fonte: Autores, 2014.

De acordo com verificação in loco, os melhores resultados estão definidos no PNMDS e no PNMLM, no âmbito ambiental. O PNMLM obteve a pontuação máxima de 26,52 pontos em todos os âmbitos avaliados.

\section{CONCLUSÃO}

Através desta pesquisa, pode-se constatar que todos os parques do norte do estado do Rio Grande do Sul necessitam de atenção especial por parte de seus gestores e maiores investimentos financeiros, para que possam dar suporte na melhoria contínua da gestão. Também se observou que as UCs estudadas, que possuem Plano de Manejo, atendem a um maior número de práticas, detendo soma positiva como resultado final dos quatro âmbitos avaliados.

Através dos resultados obtidos, destaca-se a significância dessas áreas no âmbito ambiental. Observou-se a necessidade de revisão no gerenciamento desses locais 
para viabilizar que todas as práticas apontadas na metodologia utilizada sejam contempladas nos indicadores dos âmbitos avaliados.

O estudo admite uma verificação dos âmbitos que possuem melhor ou menor pontuação, demonstrando e permitindo o ajustamento da gestão das UCs, pois a partir desses resultados evidenciou-se uma ponderação para as práticas avaliadas em cada indicador.

\section{REFERÊNCIAS BIBLIOGRÁFICAS}

BRASIL. Lei No 9985 de 18 de julho de 2000. Regulamenta o art. 225, § 1o, incisos I, II, III e VII da Constituição Federal, institui o Sistema Nacional de Unidades de Conservação da Natureza e dá outras providências. Disponível em: <http://www.planalto.gov.br/ccivil_03/leis/l9985.htm>. Acesso em: 21 set. 2013.

CALANDINO, D. Influência da participação social na conservação da biodiversidade em Unidades de Conservação Brasileiras. 2016. 243 f. Tese (Doutorado em Desenvolvimento Sustentável) - Universidade de Brasília, Brasília, 2016.

CHAPE, S. et. al. Measuring the extent and effectiveness of protected areas as an indicator for meeting global biodiversity targets. Philosophical Transactions of the Royal Society B: Biological Sciences, v. 360, n. 1.454, 2005, p. 443-455.

ERVIN, J. Protected areas assessments in perspective. BioScience, 53, 2003, p. 819-822.

GALVÃO, J. M. et al. Gestão ambiental: aplicação de biodigestores. In: SIMPÓSIO DE ENGENHARIA DE PRODUÇÃO, XIII, Bauru, São Paulo. Anais do XIII SIMPEP. Bauru: Unesp, 2006, p. 1-5.

HOCKINGS, M. Systems for assessing the effectiveness of management in protected areas. BioScience, 53, 2003, p. 823-832.

. et al. HOCKINGS, M. et al. Evaluating effectiveness: a framework for assessing management effectiveness of protected areas. $2^{a}$ edition. Ed. Peter Valentine. Gland, Switzerland: IUCN, 2006.

ICMBio. Instituto Chico Mendes de Conservação da Biodiversidade. Planos de manejo. Disponível em: <http://www.icmbio.gov.br/portal/biodiversidade/unidades-de-conservacao/planos-de-manejo.html>. Acesso em: 11 set. 2013.

LEVERINGTON, F. et. al. Protected area management effectiveness assessments in Europe - Supplementary Report. Nature, 2010.

MEDEIROS, R.; IRVING, M; GARAY, I. A proteção da natureza no Brasil: evolução e conflitos de um modelo em construção. RDE - Revista de Desenvolvimento Econômico, n V, ano VI, nº 9, 2004, p. 83-93.

OLIVEIRA, D. Avaliação de efetividade de gestão de Unidades de Conservação: o mosaico do Apuí Amazonas/AM. 2012. 117 f. Dissertação (Mestrado em Desenvolvimento Sustentável) - Universidade de Brasília, Brasília, 2012.

PARRISH, J.; BRAUN, D. R.; UNNASCH, R. S. Are we conserving what we say we are? Measuring ecological integry within protected áreas. BioScience, 2003, 53, p. 851-860.

RAMOS, A. et al. Gestão de Unidades de Conservação: compartilhando uma experiência de capacitação. Realização: WWF-Brasil, Brasília, 2012. 396 p. Disponível em: <http://www.ipe.org.br/livrogestaoUC.pdf>. Acesso em: 5 set. 2013

RODRIGUES, A. S. et. al. Effectiveness of the global protected area network in representing species diversity. Nature, v. 428, n. $6.983,2004$, p. 640-643.

SANTOS, H. et al. Sistema informatizado de gestão de Unidades de Conservação - Gesto. Experiências, oportunidades e desafios do Estado do Tocantins para a excelência na conservação de Áreas Protegidas. Realização: The Nature Conservancy (TNC) e Governo do Estado do Tocantins. Palmas. Tocantins. 2012. Disponível em: <http://www.nature.org/media/brasil/gesto.pdf>. Acesso em: 4 de nov. 2013. 